\title{
Shared and Disorder-Specific Event-Related Brain Oscillatory Markers of Attentional Dysfunction in ADHD and Bipolar Disorder
}

\author{
Giorgia Michelini $^{1}$ (1) $\cdot$ Viryanaga Kitsune $^{1} \cdot$ Isabella Vainieri $^{1} \cdot$ Georgina M. Hosang ${ }^{2}$ - Daniel Brandeis ${ }^{3,4,5,6}$. \\ Philip Asherson ${ }^{1} \cdot$ Jonna Kuntsi ${ }^{1} \mathbb{C}$
}

Received: 10 October 2017 / Accepted: 25 January 2018 / Published online: 7 February 2018

(c) The Author(s) 2018. This article is an open access publication

\begin{abstract}
Attention-deficit/hyperactivity disorder (ADHD) and bipolar disorder (BD) often present with overlapping symptoms and cognitive impairments, such as increased fluctuations in attentional performance measured by increased reaction-time variability (RTV). We previously provided initial evidence of shared and distinct event-related potential (ERP) impairments in ADHD and BD in a direct electrophysiological comparison, but no study to date has compared neural mechanisms underlying attentional impairments with finer-grained brain oscillatory markers. Here, we aimed to compare the neural underpinnings of impaired attentional processes in ADHD and BD, by examining event-related brain oscillations during a reaction-time task under slow-unrewarded baseline and fast-incentive conditions. We measured cognitive performance, ERPs and brainoscillatory modulations of power and phase variability in 20 women with ADHD, 20 women with BD (currently euthymic) and 20 control women. Compared to controls, both ADHD and BD groups showed increased RTV in the baseline condition and increased RTV, theta phase variability and lower contingent negative variation in the fast-incentive condition. Unlike controls, neither clinical group showed an improvement from the slow-unrewarded baseline to the fast-incentive condition in attentional P3 amplitude or alpha power suppression. Most impairments did not differ between the disorders, as only an adjustment in beta suppression between conditions (lower in the ADHD group) distinguished between the clinical groups. These findings suggest shared impairments in women with ADHD and BD in cognitive and neural variability, preparatory activity and inability to adjust attention allocation and activation. These overlapping impairments may represent shared neurobiological mechanisms of attentional dysfunction in ADHD and BD, and potentially underlie common symptoms in both disorders.
\end{abstract}

Keywords ADHD $\cdot$ Bipolar disorder $\cdot$ EEG $\cdot$ Brain oscillations $\cdot$ Event-related potentials $\cdot$ Adults

Handling Editor: Micah M. Murray.

Electronic supplementary material The online version of this article (https://doi.org/10.1007/s10548-018-0625-z) contains supplementary material, which is available to authorized users.

Jonna Kuntsi

jonna.kuntsi@kcl.ac.uk

1 Institute of Psychiatry, Psychology and Neuroscience, Social, Genetic and Developmental Psychiatry Centre, King's College London, De Crespigny Park, London SE5 8AF, UK

2 Centre for Psychiatry, Wolfson Institute of Preventive Medicine, Barts \& The London School of Medicine \& Dentistry, Queen Mary, University of London, London, UK

3 Department of Child and Adolescent Psychiatry and Psychotherapy, Central Institute of Mental Health, Medical Faculty Mannheim/Heidelberg University, Mannheim, Germany
4 Department of Child and Adolescent Psychiatry and Psychotherapy, Psychiatric Hospital, University of Zurich, Zurich, Switzerland

5 Center for Integrative Human Physiology, University of Zurich, Zurich, Switzerland

6 Neuroscience Center Zurich, University of Zurich, Zurich, Switzerland 


\section{Introduction}

The abilities to regulate alertness and sustain attention are essential for efficient information processing and behavior (Posner and Petersen 1990). Such cognitive processes are traditionally measured with reaction time variability (RTV), capturing the consistency and short-term fluctuations in response speed during attentional performance in cognitive tasks (Kuntsi et al. 2013; Ode et al. 2011). Increases in RTV are characteristic of several psychiatric disorders (Kaiser et al. 2008), including attention-deficit/ hyperactivity disorder (ADHD) (Kofler et al. 2013; Wood et al. 2010) and bipolar disorder (BD) (Brotman et al. 2009; Moss et al. 2016). ADHD and BD are common psychiatric conditions in adults (Merikangas et al. 2011; Willcutt 2012), which severely impact many aspects of individuals' lives (Asherson et al. 2014; Skirrow et al. 2012). Although ADHD and BD represent distinct disorders, they present with common symptoms of distractibility and difficulty concentrating, which can lead to uncertainty regarding the boundaries of the two disorders (Asherson et al. 2014; Kitsune et al. 2016). These overlapping symptoms may reflect, at the cognitive level, the common fluctuations in attentional performance and increased RTV displayed by individuals with ADHD and BD (Albaugh et al. 2017; Kuntsi et al. 2014). Increased RTV is also observed in unaffected first-degree relatives of individuals with either disorder, compared to individuals without family risk, representing a candidate marker of genetic/familial risk for both disorders (Adleman et al. 2014; Andreou et al. 2007). Direct comparisons of impairments in attentional performance between ADHD and BD may lead to new insights into the pathways to overlapping symptoms and cognitive dysfunction in both disorders. Yet, cross-disorder comparisons in ADHD and BD are limited to date (Michelini et al. 2016; Rommel et al. 2016; Torralva et al. 2011).

Previous research on RTV in psychiatric disorders has addressed the question of whether dysfunctions in alertness and attentional performance, rather than being stable, could be malleable and sensitive to context changes, such as task manipulations. RTV impairments in children and adolescents with ADHD are maximal in slow and unrewarded conditions, but with the introduction of faster event rate and incentives may improve significantly more than in neurotypical individuals (Andreou et al. 2007; Cheung et al. 2017; Kuntsi et al. 2013; Slusarek et al. 2001; Uebel et al. 2010). It remains unknown, however, whether RTV also improves in adults with ADHD. Initial evidence also indicates potential malleability of RTV in $\mathrm{BD}$, as suggested by one study showing increased RTV in individuals with $\mathrm{BD}$ in a continuous performance task (CPT) with low target frequency, but not with high target frequency (Moss et al. 2016). The evidence of malleability in RTV is clinically relevant, as it may point to room for improvement in the observed cognitive impairment, which could be targeted in new interventions for the disorders, aimed at reaching and maintaining an optimal state of alertness (Cheung et al. 2017; Kuntsi and Klein 2012). Understanding whether the same or different mechanisms underlie attentional fluctuations and their potential reduction in individuals with ADHD and BD may thus potentially inform the development of interventions for ADHD and BD. No study to date, however, has compared adults with ADHD and adults with BD on the malleability of attentional fluctuation indexed by RTV.

The investigation of brain responses using the millisecond temporal precision of electroencephalography (EEG) can help elucidate the neural correlates of a suboptimal attentional performance. Most EEG studies on attentional impairments in ADHD or BD samples have employed eventrelated potentials (ERPs), measuring transient enhancements in brain activity following an event (Luck 2014). ERP studies in adults with ADHD have shown attenuated contingent negative variation (CNV) components over central regions (reflecting atypical response anticipation and preparation) (McLoughlin et al. 2010; Michelini et al. 2016; Valko et al. 2009) and reduced attentional $P 3$ components over parietal regions (reflecting impaired attentional resource allocation) (Cheung et al. 2017, 2016; McLoughlin et al. 2010; Szuromi et al. 2011). Similarly, impairments in $\mathrm{P} 3$ and CNV in BD during attentional tasks have also been found (Fridberg et al. 2009; Li et al. 2015; Maekawa et al. 2013). Yet, only a few direct comparisons have examined whether cognitive and ERP indices are affected to a similar extent in ADHD and $B D$. In a recent investigation using a cued CPT paradigm, we showed that increased RTV and reduced CNV may represent shared attentional impairments in ADHD and BD (Michelini et al. 2016). Using quantitative EEG (QEEG), we further reported that both ADHD and BD groups showed higher spontaneous EEG theta power during rest and a lack of a task-related increase in theta from rest to CPT task compared to controls (Rommel et al. 2016). These results indicate potentially shared impairments in attentional processes in both disorders. Yet, in ERP analyses, the attentional P3 components in response to cue and target stimuli were intact in both groups, consistent with other studies that also failed to report $\mathrm{P} 3$ reductions in adults with ADHD (Dhar et al. 2010; Grane et al. 2016; Michelini et al. 2016) or BD (Bestelmeyer 2012; Chun et al. 2013; Michelini et al. 2016). One possible reason for inconsistencies between studies using different attentional paradigms is that the attentional $\mathrm{P} 3$, similar to RTV, may reflect a context-dependent and potentially malleable, rather than stable, impairment (Cheung et al. 2017). We recently reported that a reduced parietal P3 in a slow and unrewarded condition in adolescents and young adults 
with ADHD improved with faster event rate and rewards significantly more than in neurotypical controls (Cheung et al. 2017). In contrast, for CNV, the ADHD group showed reduced amplitude compared to controls only in the fast and rewarded condition. No study has examined the malleability of these ERPs with faster rate and incentives in BD. Further direct comparisons between ADHD and BD are needed to clarify what neurophysiological impairments overlap between the two disorders, and whether ADHD and BD may show similar malleability with a changed context.

Advances in EEG methods called time-frequency analyses, combining the strengths of ERP and QEEG methods, further allow to capture event-related brain oscillatory dynamics, which reflect sub-second modulations of power and phase in response to an event across the full EEG spectrum (Klimesch 1999; Loo et al. 2015; Makeig et al. 2004; Pfurtscheller and Lopes da Silva 1999). Processing and focusing attention on a relevant stimulus have been associated with various event-related brain oscillatory phenomena in the time-frequency domain not captured by ERP or QEEG approaches: (1) an event-related synchronization (ERS) or increase in theta (3-7 Hz) power over fronto-central (Bickel et al. 2012; Lenartowicz et al. 2014; Mazaheri et al. 2014) or parietal (Babiloni et al. 2004; Jacobs et al. 2006) regions, reflecting the initial processing of the stimulus; (2) an event-related desynchronization (ERD) or suppression of power in posterior alpha $(8-13 \mathrm{~Hz})$, reflecting attentional selection and cortical activation (Klimesch 2012; Mazaheri and Picton 2005); and (3) an ERD in central beta $(14-30 \mathrm{~Hz})$ when a motor response is required (Guntekin et al. 2013; Pfurtscheller 1981). Additionally, indices of consistency of the phase (i.e., the "timing") of brain oscillations over trials can reveal whether the processing of a stimulus repeated over time reflects stable or variable neural mechanisms (Klimesch 2012; Makeig et al. 2004; Papenberg et al. 2013). Greater alpha and beta ERD and theta phase consistency have further been associated with better task performance (Bickel et al. 2012; Klimesch 2012; McLoughlin et al. 2014). Multiple brain-oscillatory correlates of attentional processes may be affected in ADHD and BD. Individuals with ADHD have been reported to show reductions in event-related phase consistency in the theta band (Groom et al. 2010; McLoughlin et al. 2014), alpha ERD (Lenartowicz et al. 2014; ter Huurne et al. 2013), and beta ERD (Hasler et al. 2016). Emerging evidence also suggests that individuals with BD show attenuations in event-related theta (Atagun et al. 2013; Ethridge et al. 2012) and alpha power (Basar et al. 2012; Ethridge et al. 2012) and increases in beta power (Ozerdema et al. 2013; Tan et al. 2016). These studies in BD, however, applied time-frequency analyses on averaged ERP responses, thus not allowing the characterization of both ERD and ERS dynamics (Bickel et al. 2012). The investigation of fine-grained brain-oscillatory indices underlying attentional processes with time-frequency analyses may allow a deeper investigation into the neural correlates of attentional performance, and help identify distinct or comparable impairments in neural processes between the two disorders (Loo et al. 2015). However, no study to date has compared ADHD and BD on time-frequency indices of brain oscillations, or whether these indices, like RTV, show adjustments under context changes, such as fast and rewarded conditions.

The present study aims to investigate and compare cognitive-performance, ERP and detailed event-related power modulations of theta, alpha and beta oscillations and of phase variability in theta oscillations, previously linked to attentional processes, in adults with ADHD and adults with BD. We used an all-female sample, to match the groups on sex but also because little is known on these processes in females, especially in relation to ADHD (McLoughlin et al. 2010; Saville et al. 2015). Participants completed the same four-choice reaction time task used in our previous studies of ADHD (Andreou et al. 2007; Cheung et al. 2017; Kuntsi et al. 2006), which compares a slow-unrewarded baseline condition with a fast-incentive condition designed to specifically reward reduction of RTV. A further aim is to examine whether differences in adjustments in the investigated cognitive-performance, ERP and brain-oscillatory indices with a faster event rate and incentives emerge between groups, which could inform the development of cognitive/brain training programs for $\mathrm{ADHD}$ and $\mathrm{BD}$.

\section{Methods}

\section{Sample}

The sample consisted of 20 women with ADHD, 20 with BD and 20 control women, aged between 20 and 52 years (Table 1). Full information on recruitment and clinical assessment of this sample can be found elsewhere (Kitsune et al. 2016). Briefly, participants with ADHD were recruited from the National Adult ADHD Clinic at the Maudsley Hospital, where any adult female cases meeting inclusion

Table 1 Sample demographics divided by group, with ANOVA test for group differences

\begin{tabular}{llllll}
\hline & $\begin{array}{l}\text { ADHD } \\
\text { Mean (SD) }\end{array}$ & $\begin{array}{l}\text { BD } \\
\text { Mean (SD) }\end{array}$ & $\begin{array}{l}\text { Ctrl } \\
\text { Mean (SD) }\end{array}$ & F & p \\
\hline Age & $37.4(7.7)$ & $40.3(7.7)$ & $36.7(4.3)$ & 1.63 & 0.21 \\
IQ & $104(17.9)$ & $108(12.5)$ & $112(14.2)$ & 1.37 & 0.26 \\
\hline
\end{tabular}

Group differences on age and IQ were tested with univariate ANOVAs

$A D H D$ attention-deficit/hyperactivity disorder, $B D$ bipolar disorder, $C$ trl control group, $F$ ANOVA statistic, $p$ p value from the ANOVA 
criteria were considered for potential inclusion in the study. Participants with BD were recruited from the Maudsley Psychosis Clinic and a sample that had previously participated in another research study (Hosang et al. 2012). Control participants were recruited from the Mindsearch volunteer database maintained by the Institute of Psychiatry, Psychology and Neuroscience, King's College London, which comprises several thousand potential participants. Participants were randomly selected from all those meeting recruitment criteria for this study.

Diagnosis in the clinical groups was confirmed by checking medical records for details of diagnosis and psychiatric history, following DSM-IV criteria. Fifty-seven women with ADHD, 75 women with BD, and 120 control women who matched requirements of age, gender and clinical diagnosis based upon DSM-IV criteria were approached to participate. Among individuals willing to participate (30 with ADHD, 29 with BD and 32 controls), participants were selected for inclusion in the study based on the following exclusion criteria (Kitsune et al. 2016). Exclusion criteria for all groups were drug or alcohol dependency in the last 6 months, autism, epilepsy, neurological disorders, brain injury, past ECT treatment, current involvement in another research trial likely to alter symptom severity, pregnancy or a limited proficiency in English language. Individuals with ADHD and individuals with $\mathrm{BD}$ with a reported comorbidity of both $\mathrm{ADHD}$ and $\mathrm{BD}$ were also excluded. Individuals with BD group who were experiencing a manic episode at the time of the assessment were excluded; only participants who were euthymic at the time of participation were included in the BD group. Control participants, who reported a history of psychiatric disorders or who were taking psychiatric medication, were excluded from the study. Comorbidity in the clinical groups and lack of psychiatric disorders in the control group were further assessed through clinical evaluations when participants underwent the cognitive-EEG assessment for this study (Kitsune et al. 2016). An ADHD diagnosis was excluded in the BD group after conducting the Diagnostic Interview for Adult ADHD (DIVA v. 2.0; (Ramos-Quiroga et al. 2016)). A BD diagnosis was excluded in the ADHD group by checking for a history of past episodes of depression or hypomania/mania and evaluating current mood symptoms using the Altman Self-Rating Mania Scale (Altman et al. 1997) and the Beck Depression Inventory (Beck et al. 1996), and current and lifetime ever symptoms using the Young Mania Rating Scale (Young et al. 1978).

All participants underwent a thorough clinical evaluation with gold-standard diagnostic tools as part of this study; full information on clinical profiles and severity of $\mathrm{ADHD}$ or $\mathrm{BD}$ in the clinical groups can be found in Kitsune et al. 2016. Participants in the ADHD group had a current combined-type diagnosis or an inattentive-type diagnosis with sufficient symptoms of hyperactivity-impulsivity in childhood to meet a childhood combined-type diagnosis, which reflects the typical adult ADHD clinical population (Asherson et al. 2014). Participants in the BD group had a diagnosis of BD Type I, having experienced at least one manic episode lasting 1 week or more in the past, but were euthymic at the time of the assessments. The ADHD and BD groups did not differ significantly on any of the mood scales for current symptoms, but the ADHD group showed significantly greater levels of ADHD symptoms (e.g., total ADHD symptoms according to the DIVA interview: mean $=13.45$, $\mathrm{SD}=3.02$ in the ADHD group, mean $=4.95, \mathrm{SD}=3.27$ in the BD group) (Kitsune et al. 2016).

\section{Procedure}

Participants attended a single 4.5-h research session (including breaks) for cognitive-EEG assessment, IQ assessment and clinical interviews. Participants' IQs were assessed with the Wechsler Abbreviated Scale of Intelligence Fourth Edition (WASI-IV; (Wechsler 1999)) and did not differ between groups. All participants were asked to refrain from caffeinated drinks and nicotine $2 \mathrm{~h}$ before assessments. Participants with ADHD were asked to stop taking any stimulant medication prescribed for their ADHD $48 \mathrm{~h}$ prior to the assessment. On the day of the assessments, all ADHD participants who were taking stimulant medication $(n=13)$ confirmed that they had stopped medication in the preceding $48 \mathrm{~h}$. For ethical reasons, participants were not asked to stop taking mood stabilizers (70\% of the BD group), anti-psychotic medication ( $40 \%$ of the BD group) or anti-depressants ( $7 \%$ of the ADHD group and 25\% of the BD group) they had been prescribed. Ethical approval for the study was granted by the Camberwell St Giles Research Ethics Committee (approval number 11/LO/0438) and all participants provided informed consent.

\section{Fast Task}

The task for this analysis was a computerized four-choice reaction time task which measures performances under a slow-unrewarded and a fast-incentive condition (Andreou et al. 2007; Kuntsi et al. 2006). In both conditions speed and accuracy were emphasized equally. The baseline (slowunrewarded) condition followed a standard warned fourchoice reaction-time task (Fig. S1, Supplementary material). A warning signal (four empty circles, arranged side by side) first appeared on the screen. At the end of the fore-period lasting $8 \mathrm{~s}$ (presentation interval for the warning signal), the circle designated as the target signal for that trial was filled (colored) in. The participant was asked to make a compatible choice by pressing the response key that directly corresponded in position to the location of the target stimulus. Following a response, the stimuli disappeared from the screen and a fixed inter-trial interval of $2.5 \mathrm{~s}$ followed. If the 
participant did not respond within $10 \mathrm{~s}$, the trial terminated. First, a practice session was administered, during which the participant had to respond correctly to five consecutive trials. The baseline condition, consisting of 72 trials, then followed.

To investigate the extent to which a response style characterized by slow and variable speed of responding may be reduced, the task includes a comparison condition that uses a fast event rate (fore-period of $1 \mathrm{~s}$ ) and incentives (Fig. S1, Supplementary material). This condition started immediately after the baseline condition and consisted of 80 trials, with a fixed inter-trial interval of 2.5 s following the response. The participants were told to respond as quickly as possible to each target, in order to win smiley faces and earn real prizes at the end. Participants won a smiley face for responding faster than their own mean reaction time (MRT) during the baseline (first) condition consecutively for three trials. The baseline MRT was calculated here based on the middle $94 \%$ of responses (the exclusion of the top and bottom $3 \%$ of responses is only used when calculating a baseline MRT for the set-up of the fast-incentive condition, and is not used for analyses), therefore excluding extremely fast and extremely slow responses. The smiley faces appeared below the circles in the middle of the screen and were updated continuously. The fast-incentive condition was always administered after the baseline condition and, as such, did not involve a similar learning phase. Participants earned $£ 5$ in cash after the task battery. RTV for correct responses in each condition was measured to assess task performance.

\section{EEG Recording and Pre-processing}

The EEG was recorded from a 62-channel DC-coupled recording system (extended 10-20 montage) (Brain Products, Gilching, Germany), using a $500 \mathrm{~Hz}$ sampling-rate, impedances under $10 \mathrm{k} \Omega$, and $\mathrm{FCz}$ as the recording reference. The electro-oculograms (EOGs) were recorded from electrodes above and below the left eye and at the outer canthi. EEG recordings were pre-processed and analyzed using the EEGLAB toolbox (Delorme and Makeig 2004) in Matlab (MathWorks, Natick, MA, USA). Researchers were blind to group status during EEG pre-processing and analysis. Raw EEG recording were down-sampled to $256 \mathrm{~Hz}$, re-referenced to the average of all electrodes (turning $\mathrm{FCz}$ into an active channel), and digitally filtered using a $0.25 \mathrm{~Hz}(-6 \mathrm{~dB}$ cutoff) high-pass filter and a $35 \mathrm{~Hz}$ ( $-6 \mathrm{~dB}$ cut-off) low-pass filter. Independent component analysis (ICA) (Jung et al. 2000) was used to identify and remove ocular (blink-related and vertical and horizontal eye movements) and muscular artefacts. Visual inspection was carried out for all trials to manually remove further artefacts. Channels showing technical problems or excessive electrical noise were removed and replaced with topographic spline interpolation after ICA, to estimate a virtual EEG activity based on artefact-free activity from other channels.

\section{ERP and Time-Frequency Analyses}

Only participants with at least 20 artefact-free EEG segments in each condition were included in ERP/EEG analyses. All ERP/EEG analyses were performed using EEGLAB functions (Delorme and Makeig 2004) and Matlab custom scripts. ERP analyses were restricted to ERP components relevant for attentional processes previously found atypical in studies in ADHD or BD (Cheung et al. 2017; Michelini et al. 2016; Li et al. 2015). ERP peaks were identified within the selected electrodes and latency windows for which effects were expected to be maximal, based on our previous ERP analyses of this task (Cheung et al. 2017; James et al. 2017) and verified against the topographic maps and the grand averages (Fig. 1, Fig. S2, Supplementary material). Following our previous work (Cheung et al. 2017), P3 amplitudes were analyzed at $\mathrm{Pz}$ between 300 and $550 \mathrm{~ms}$ (Fig. S2, Supplementary material) following the target as the area amplitude measure $(\mu \mathrm{V} \cdot \mathrm{ms})$, to reduce bias due to the varying noise levels induced by the different task conditions (Luck 2014). All trials were baseline-corrected by subtracting the mean activity (200 ms before target onset) from the P3 ERPs. The mean amplitudes of this pre-target period between -200 and $0 \mathrm{~ms}$ were also analyzed separately as a CNV measure at $\mathrm{Cz}$ (Fig. 1) with technical zero-baseline approach (which measures the absolute state rather than the amount of neural change introduced by the event) following previous CNV work (Albrecht et al. 2013; Banaschewski et al. 2003; Cheung et al. 2017). This short CNV interval, characterized by a typical CNV topography in the fast-incentive condition with its $1000 \mathrm{~ms}$ warning-target interval, was chosen as it captures the late CNV component unconfounded by the processing of warning stimuli. Although no typical CNV emerged in the slower baseline condition, CNV amplitude at $\mathrm{Cz}$ in the same corresponding time window was used to examine within-subject change in preparatory activity across conditions.

Time-frequency analyses examined the target-related modulations of power and phase consistency of brain oscillations previously implicated in attentional processes and with initial evidence of atypical profiles in ADHD or BD samples based on previous literature (Groom et al. 2010; Hasler et al. 2016; Ethridge et al. 2012). Modulations of power were quantified with the event-related spectral perturbation (ERSP) index (Delorme and Makeig 2004). ERSP values were computed in a $4000 \mathrm{~ms}$ window (from - 2000 to $2000 \mathrm{~ms}$ ) centered around target onset by applying a Morlet wavelet decomposition of frequencies between 3 and $30 \mathrm{~Hz}$, with linearly increasing number of cycles (frequency step 

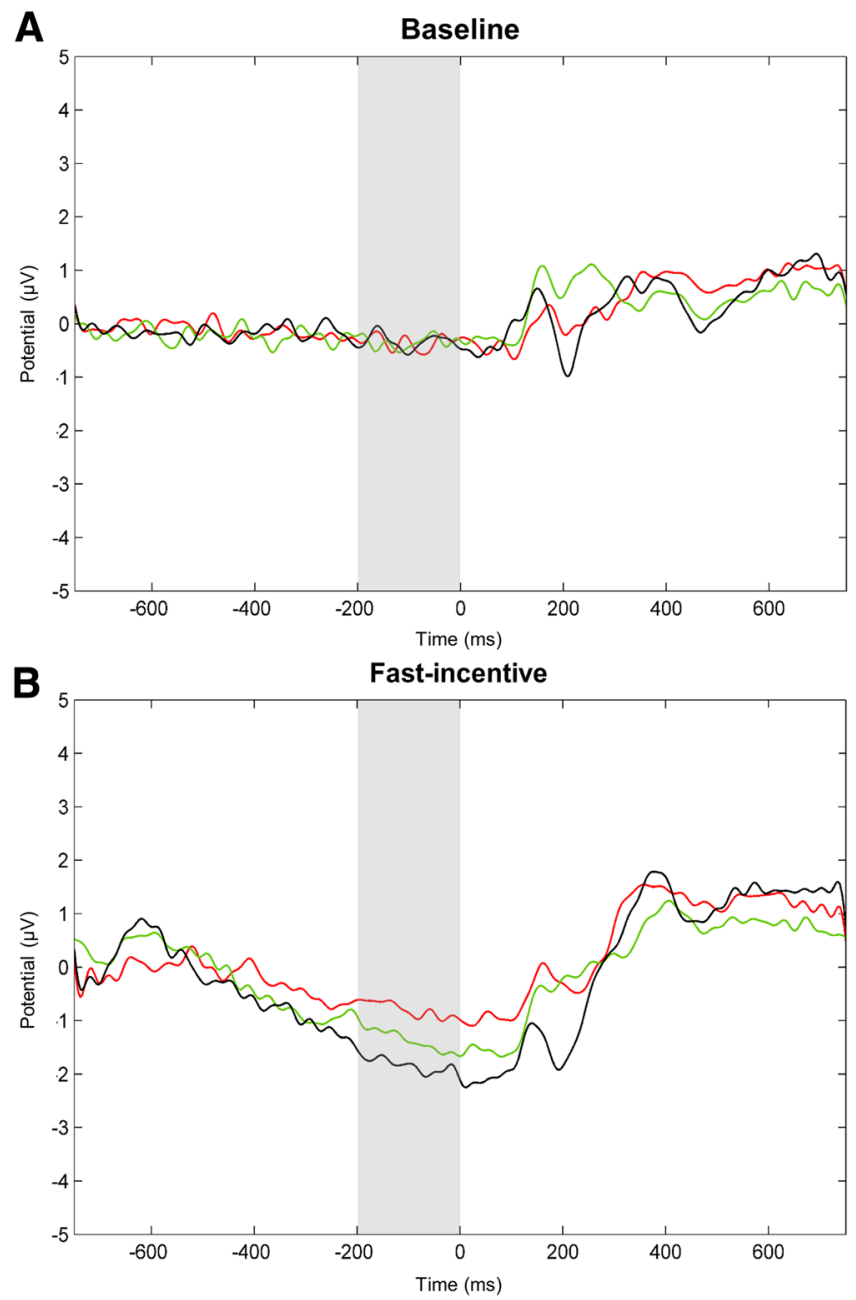

Fig. 1 Contingent negative variation (CNV) amplitude measured at $\mathrm{Cz}$ in the $-200-0 \mathrm{~ms}$ window in the ADHD (in red), BD (in green) and control (in black) groups across the baseline and fast-incentive

of $0.80 \mathrm{~Hz}$ ) from 2 cycles for the lowest frequency $(3 \mathrm{~Hz})$ to 24.60 cycles for the highest frequency $(30 \mathrm{~Hz})$. Each ERSP trial was normalized with respect to the mean logpower spectrum from the pre-stimulus period, from -2000 to $-1000 \mathrm{~ms}$, corresponding to the $1000 \mathrm{~ms}$ preceding the warning onset in the fast-incentive condition; the same comparable window was used in the baseline condition as the long fore-period before targets did not produce a modulation of power before stimulus onset in the baseline condition (see Supplementary material for further explanation). Averaging all ERSPs across trials produced a time-frequency representation in decibel $(\mathrm{dB})$ units of increases (ERS, in red) and decrease (ERD, in blue) in the spectral power at a given frequency and latency with respects to pre-stimulus activity (Figs. 2, 3), from which frequency-specific ERSPs can be extracted. Phase consistency was calculated with the intertrial phase coherence (ITC) index, measuring the degree to which the phase of the evoked response (derived from the

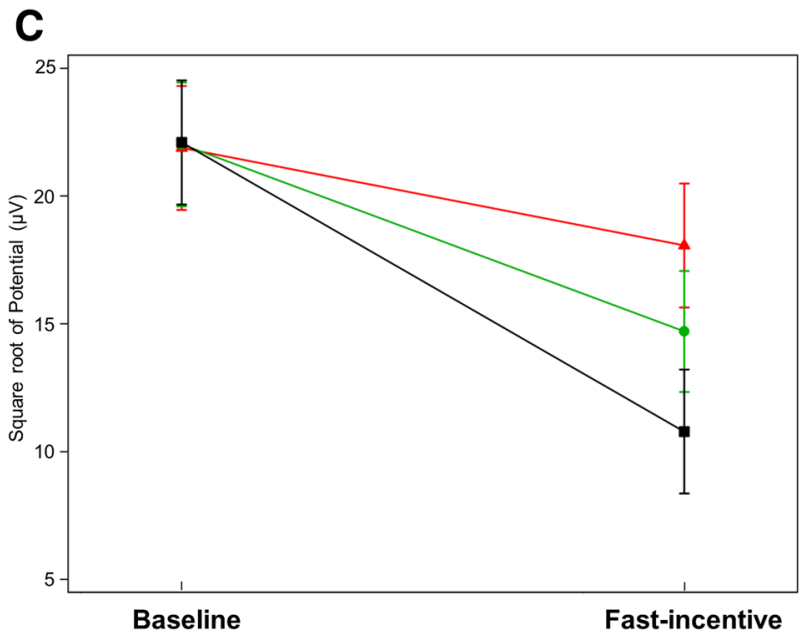

D
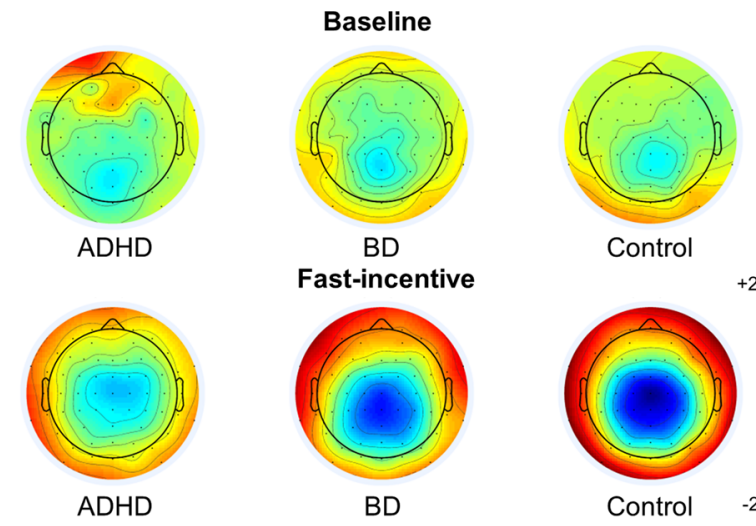

Fast-incentive

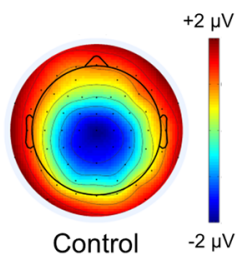

conditions of the Fast task. a Grand average in the baseline condition; b grand average in the fast-incentive condition; c condition effects by group; $\mathbf{d}$ topographic maps by group at each condition

same Morlet wavelet used for the ERSP index) at a given latency and frequency is consistent across trials (Delorme and Makeig 2004; Makeig et al. 2004; Tallon-Baudry et al. 1996). ITC values are independent of power, and range from 0 (reflecting absence of phase consistency and highest phase variability across trials) to 1 (indicating perfect phase consistency and lowest phase variability) (Fig. 4).

Target-related ERSP in the theta $(3-7 \mathrm{~Hz})$, alpha $(8-13 \mathrm{~Hz})$ and beta $(14-30 \mathrm{~Hz})$ bands were extracted in the $1000 \mathrm{~ms}$ window capturing the broad target-related modulation of power, divided into two consecutive windows for earlier (0-500 ms) and later (500-1000 ms) processing (Figs. 2, 3, Fig. S3, Supplementary material). ITC was measured at target onset in the first window $(0-500 \mathrm{~ms})$, where greater phase consistency in response to the event was observed (Fig. 4), as expected (Groom et al. 2010). The ITC analysis was restricted to the theta band, consistent with previous studies reporting a role of this frequency band in neural 

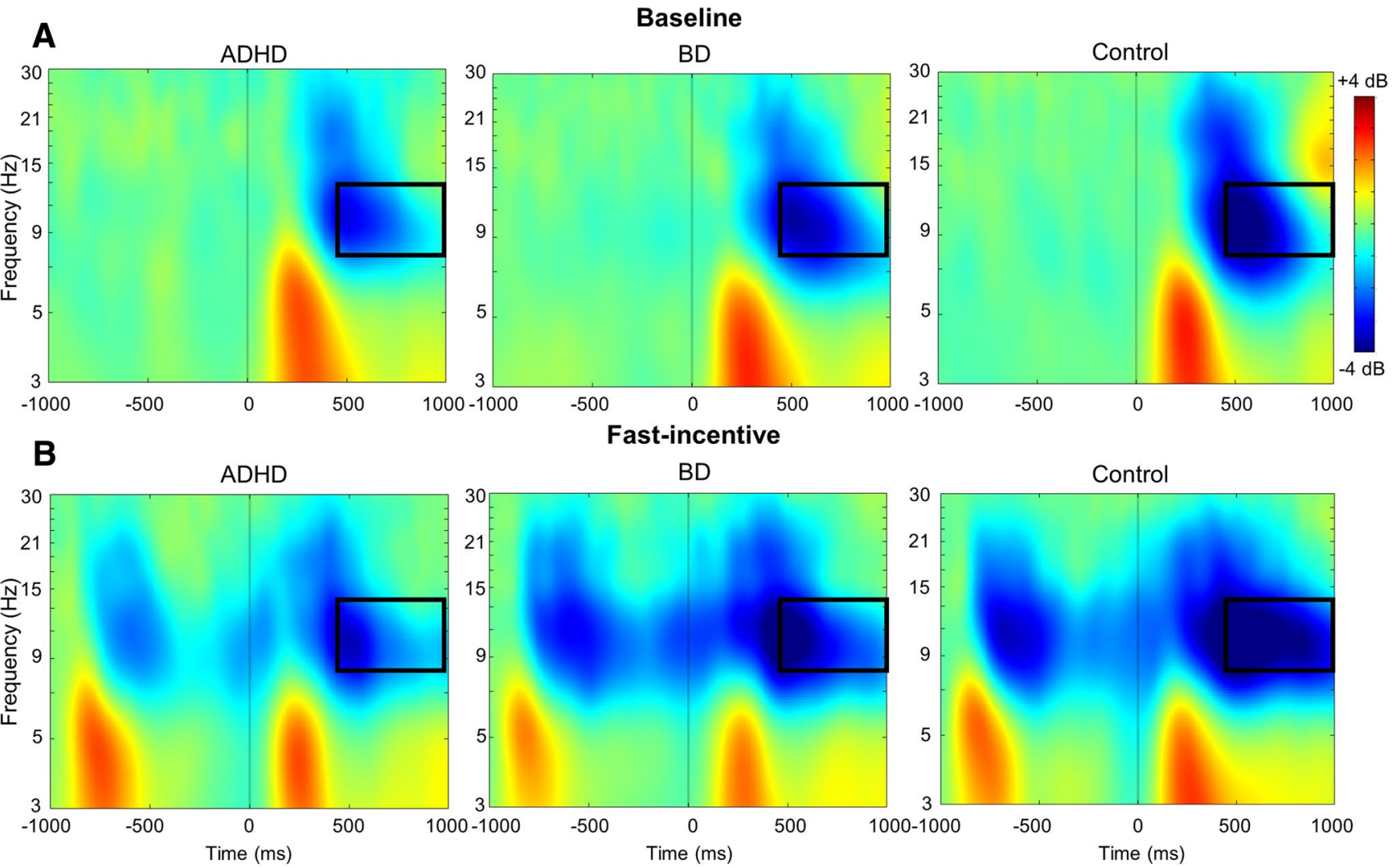

C

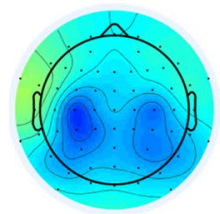

$\mathrm{ADHD}$

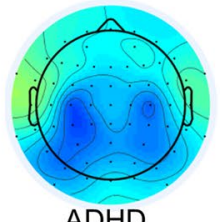

ADHD

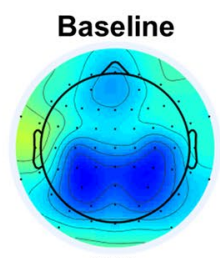

$\mathrm{BD}$
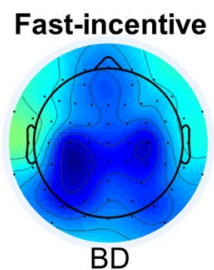

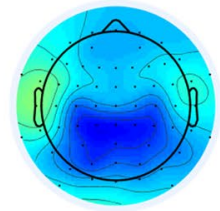

Control

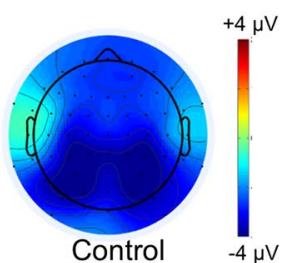

D

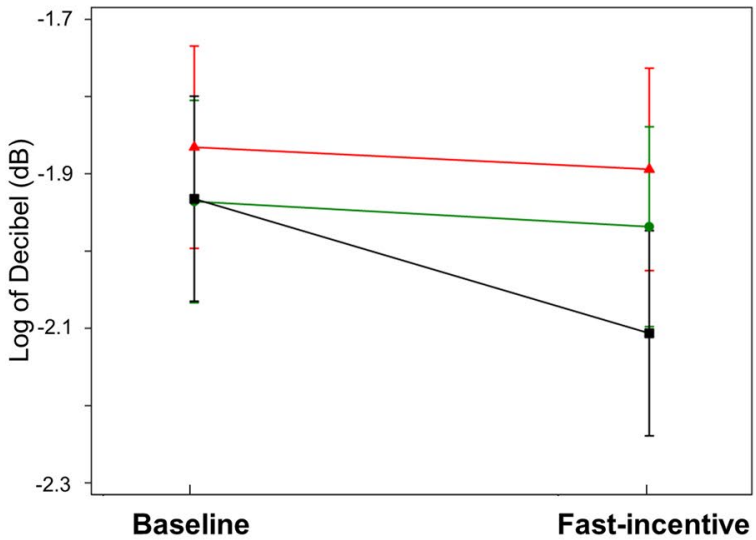

Fig. 2 Alpha event-related spectral perturbation (ERSP) at parietooccipital regions in the ADHD, BD and control groups in the baseline and fast-incentive condition of the Fast task. a ERSP in the baseline conditions; b ERSP in the fast-incentive condition; c topographic maps by group in the $500-1000 \mathrm{~ms}$ window at each condition; $\mathbf{d}$ condition effects in the $500-1000 \mathrm{~ms}$ window by group (ADHD group in red, BD group in green, control group in black)

and Picton 2005); beta over central regions (average of electrodes: Cz, C1-C4, CPz, CP1-CP4) (Bickel et al. 2012; Mazaheri and Picton 2005).

\section{Statistical Analyses}

All measures were investigated using random intercept linear models (i.e., multilevel regression models). Main effects of group (ADHD vs BD vs control), condition 

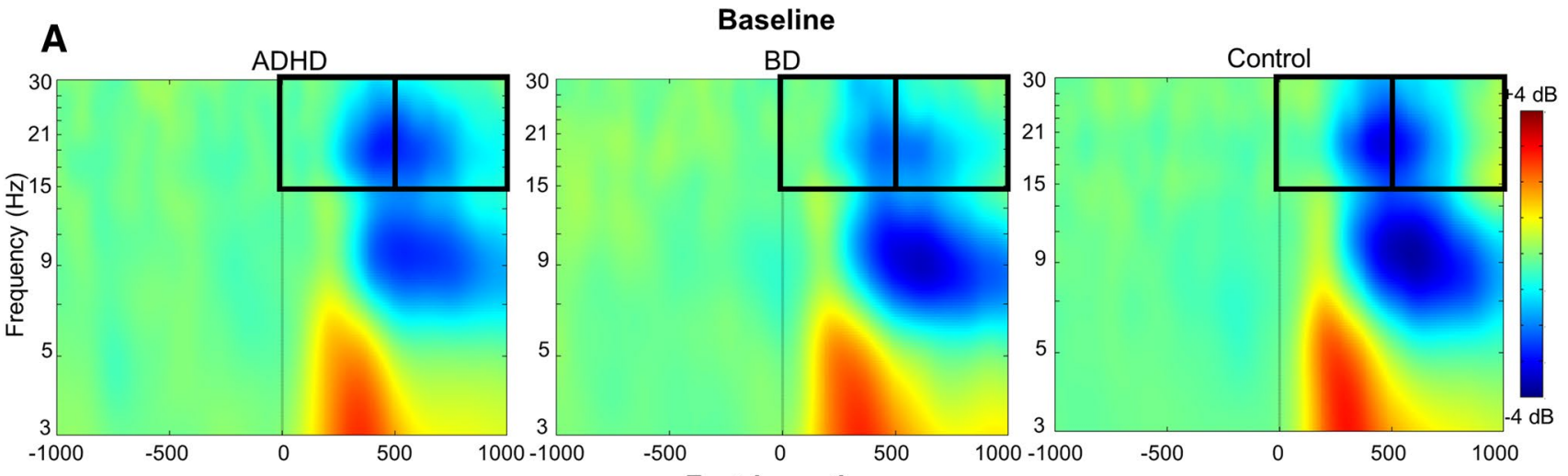

B

Fast-incentive
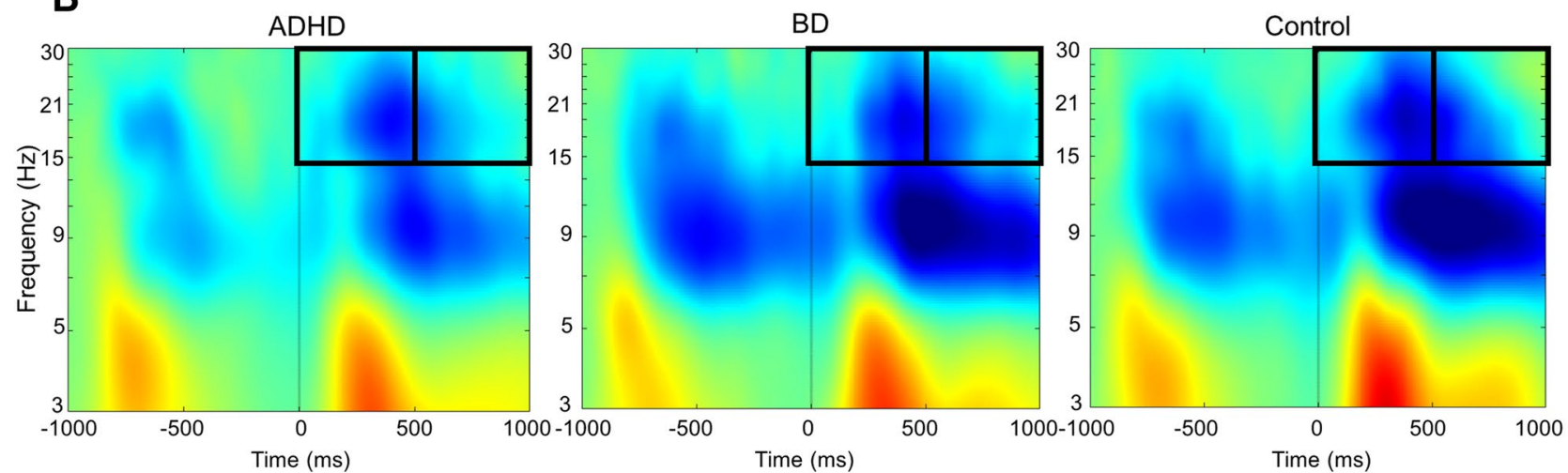

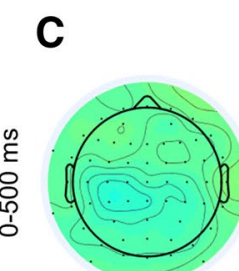

ADHD

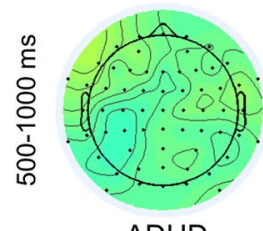

ADHD

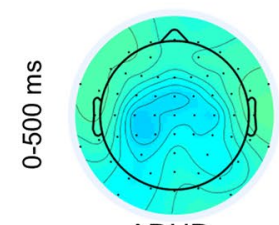

ADHD

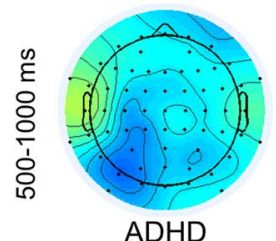

\section{Baseline}

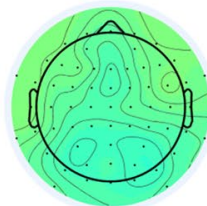

BD

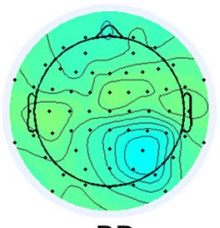

BD

Fast-incentive

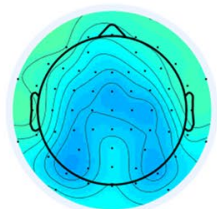

BD

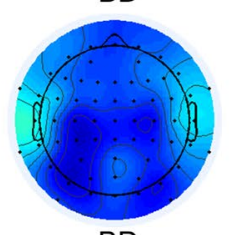

BD

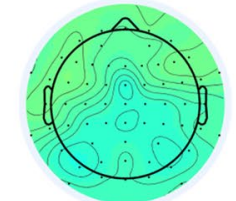

Control
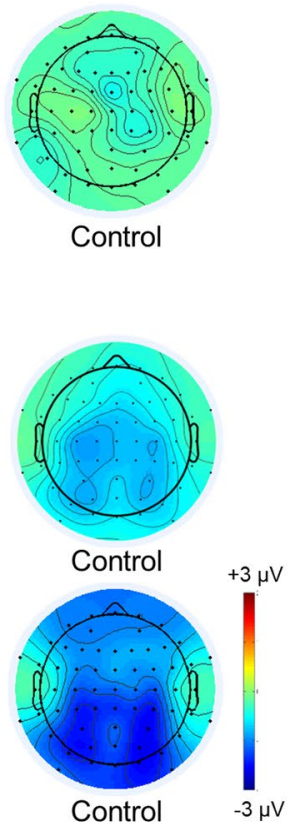

D

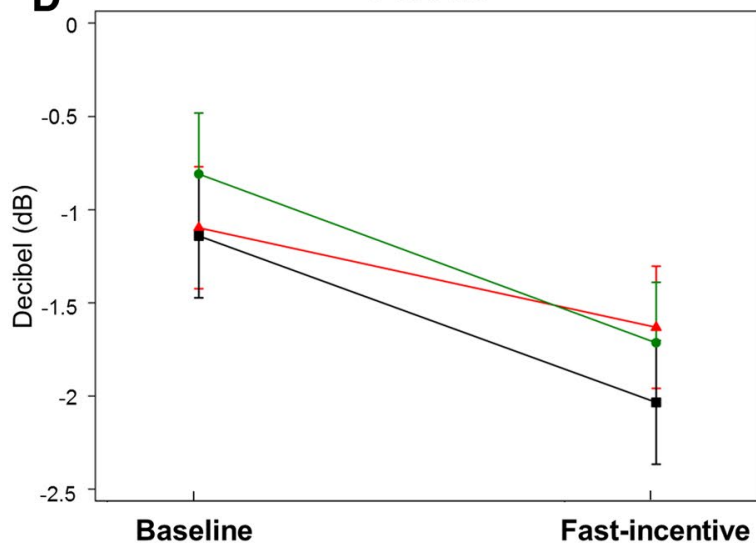

$500-1000 \mathrm{~ms}$

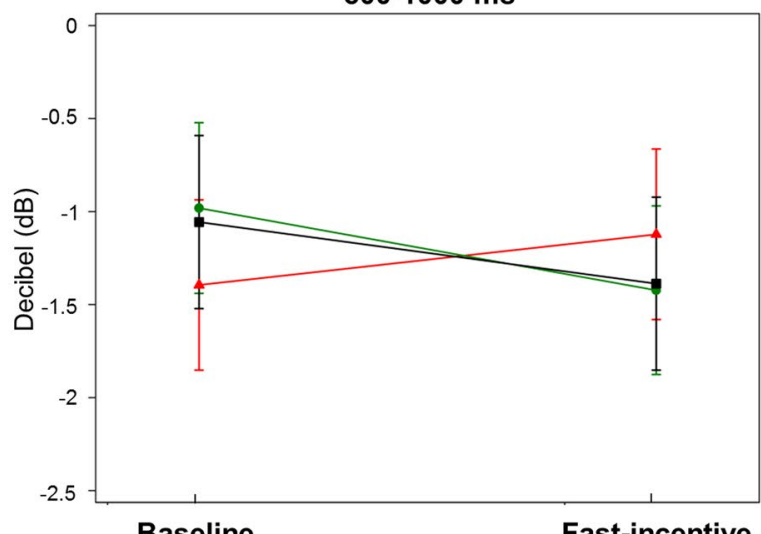


4Fig. 3 Beta event-related spectral perturbation (ERSP) at central regions in the ADHD, BD and control groups in the baseline and fastincentive conditions of the Fast task. a ERSP in the baseline condition; $\mathbf{b}$ ERSP in the fast-incentive condition; $\mathbf{c}$ topographic maps by group in the $0-500 \mathrm{~ms}$ and $500-1000 \mathrm{~ms}$ windows at each condition; d condition effects at each time window by group (ADHD group in red, BD group in green, control group in black)

(baseline vs fast-incentive) and group-by-condition interactions were examined. Significant $(\mathrm{p}<0.05)$ and trendlevel $(\mathrm{p}<0.10)$ effects were followed up with post-hoc analyses testing for (1) between-group differences in baseline and fast-incentive conditions separately, and (2) within- and between-group effects of change between conditions with difference scores. Since ERSP indices were measures at two time windows (0-500, 500-1000 ms), we tested for three-way group-by-condition-by-time interactions for these measures, followed by additional post-hoc tests examining group differences in each time window. Since groups did not differ on IQ or age (Table 1), these variables were not controlled for in analyses. Measures that showed skewed distributions were transformed to normal with square root (CNV, P3) and with logarithm using the "Inskew0" Stata command (MRT, RTV, beta ERSP). In order to inform future larger-scale studies, multipletesting corrections were deemed not appropriate to limit the chance of introducing type-two errors (i.e. false negative results). Variables for analysis were restricted to measures that were expected to be sensitive to impairments in ADHD or BD to limit the number of hypotheses tested. For between-group comparisons, we report both p-values and Cohen's d effect sizes (with 95\% confidence intervals), calculated using the difference in the means divided by the pooled standard deviation, where $d \geq 0.20$ constitutes a small effect, $\mathrm{d} \geq 0.50$ a medium effect and $\mathrm{d} \geq 0.80$ a large effect (Cohen 1988). All statistical analyses were run in Stata 14 (Stata Corp, College Station, TX, USA). Data on the fast-incentive condition were missing for one participant with ADHD due to technical issues during the testing session. Two control participants had outlier RTV ( $>5$ $\mathrm{SD})$ in the baseline condition, indicating that they did not follow task instructions, and were excluded from all analyses. As at least 20 artefact-free EEG segments are needed to obtain reliable ERP/EEG indices (McLoughlin et al. 2009), one participant with ADHD and one with BD were excluded from ERP/EEG analyses on the baseline condition, and one control from ERP/EEG analyses on both conditions. Due to the longer fore-period in the baseline condition, the two conditions were matched on the number of trials, but not on length. To control for this, we run the analyses of RTV performance first on the full baseline condition, and separately on a length-matched segment of the baseline (Andreou et al. 2007) (Supplementary material). Condition length was not controlled for in the ERP/
EEG analyses, as data from the full baseline condition was required to obtain sufficient $(>20)$ trials for averaging.

\section{Results}

\section{RTV}

Significant group $(\mathrm{p}=0.01)$ and condition $(\mathrm{p}<0.001)$ effects, but no group-by-condition interaction $(p=0.92)$, emerged for RTV. Post-hoc tests of group effects showed that the ADHD and the BD groups had significantly increased RTV compared to controls in both conditions, but did not differ significantly from one another (Table 2). Post-hoc analyses of condition effects showed that all three groups had a significant within-group decrease in RTV from the baseline to the fast-incentive condition, with no significant differences between groups in the degree of change between conditions (Table 3). Comparable results were obtained using the length-matched segment of the baseline condition (Supplementary material).

\section{ERPs}

\section{CNV}

Significant main effects of group $(\mathrm{p}=0.03)$ and condition $(\mathrm{p}<0.001)$, and a significant group-by-condition interaction $(p<0.01)$, emerged for the CNV. Post-hoc tests showed no group differences in the baseline condition (Table 2). In the fast-incentive condition, the $\mathrm{CNV}$ was significantly reduced in the ADHD compared to the control group (Fig. 1). The $\mathrm{BD}$ group showed a trend-level effect for greater CNV compared to the ADHD group, and a significantly reduced CNV compared to controls (Table 2). All three groups had a significant within-group decrease from the baseline to the fast-incentive condition (Table 3; Fig. 1). The degree of change in CNV between conditions in the ADHD group was significantly lower compared to the control group, and at trend level compared to the BD group. The BD group also showed a trend-level reduction in CNV compared to the control group in the degree of change between conditions.

\section{P3}

A trend-level group-by-condition interaction $(p=0.06)$, but no main effects of group $(p=0.84)$ or condition $(p=0.56)$, emerged for the P3. Post-hoc tests did not show significant group differences in the baseline or in the fast-incentive condition (Table 2, Fig. S2, Supplementary material). A significant within-group change from the baseline to the fast-incentive condition in stimulus-locked P3 emerged in controls, but not in participants with ADHD or BD (Table 3). The degree of 

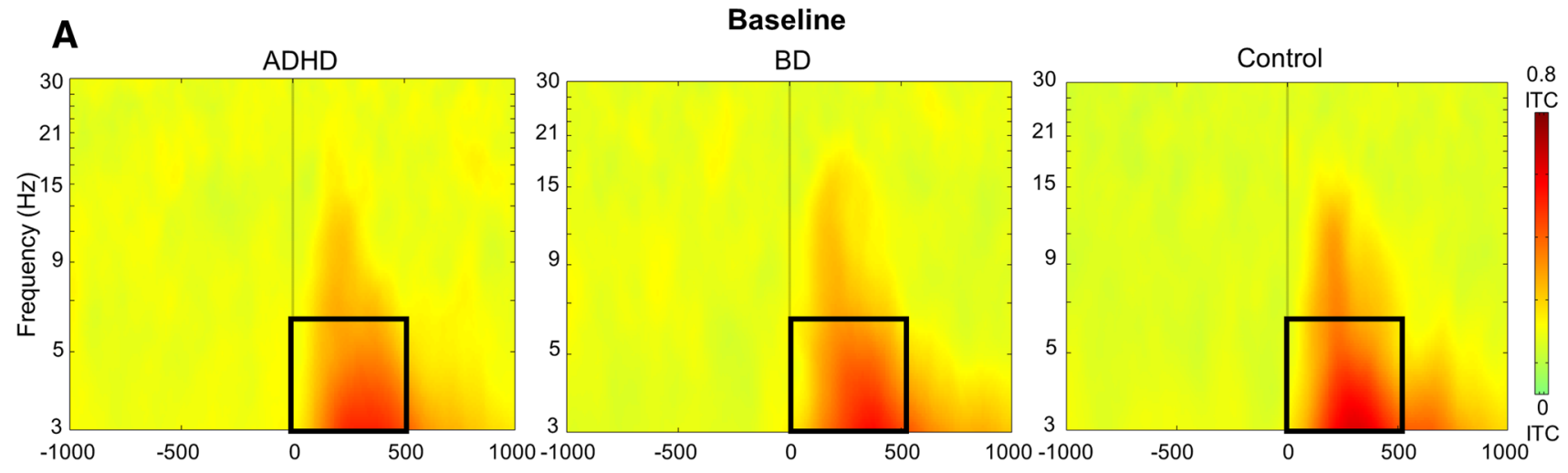

B

Fast-incentive
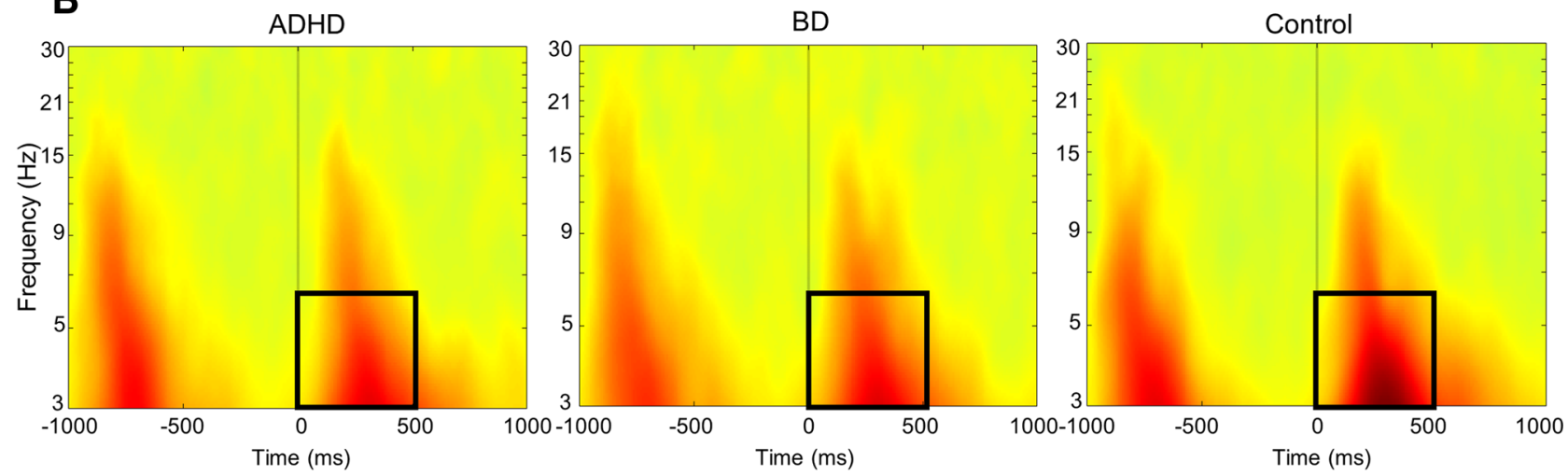

C

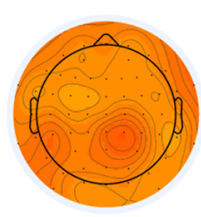

$\mathrm{ADHD}$

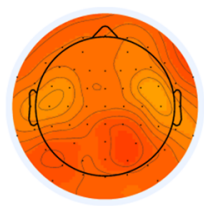

$\mathrm{ADHD}$

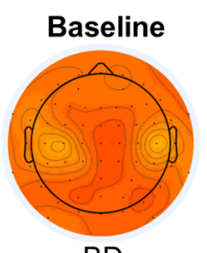

BD
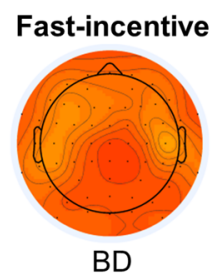

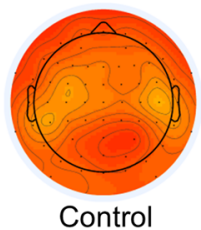

Control

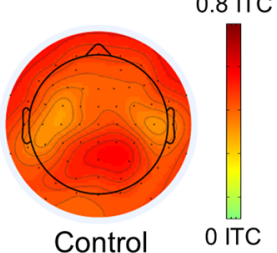

D

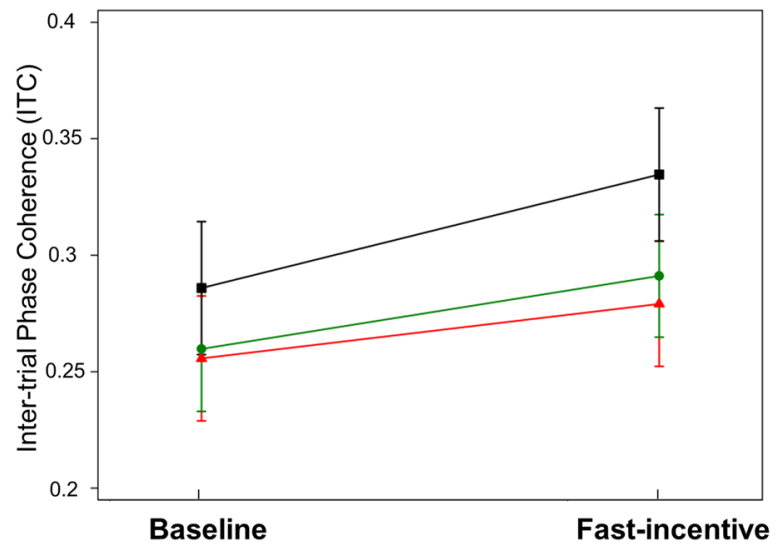

Fig. 4 Theta inter-trials phase coherence (ITC) at parietal regions in the ADHD, BD and control groups across the baseline and fastincentive conditions of the Fast task. a ITC in the baseline condition; b ITC in the fast-incentive condition; c topographic maps by group in the $0-500 \mathrm{~ms}$ window at each condition; $\mathbf{d}$ condition effects in the $500-1000 \mathrm{~ms}$ window by group (ADHD group in red, BD group in green, control group in black) change between conditions was significantly lower in the BD compared to the control group. The ADHD group did not differ significantly from the other two groups in the degree of change between conditions. 


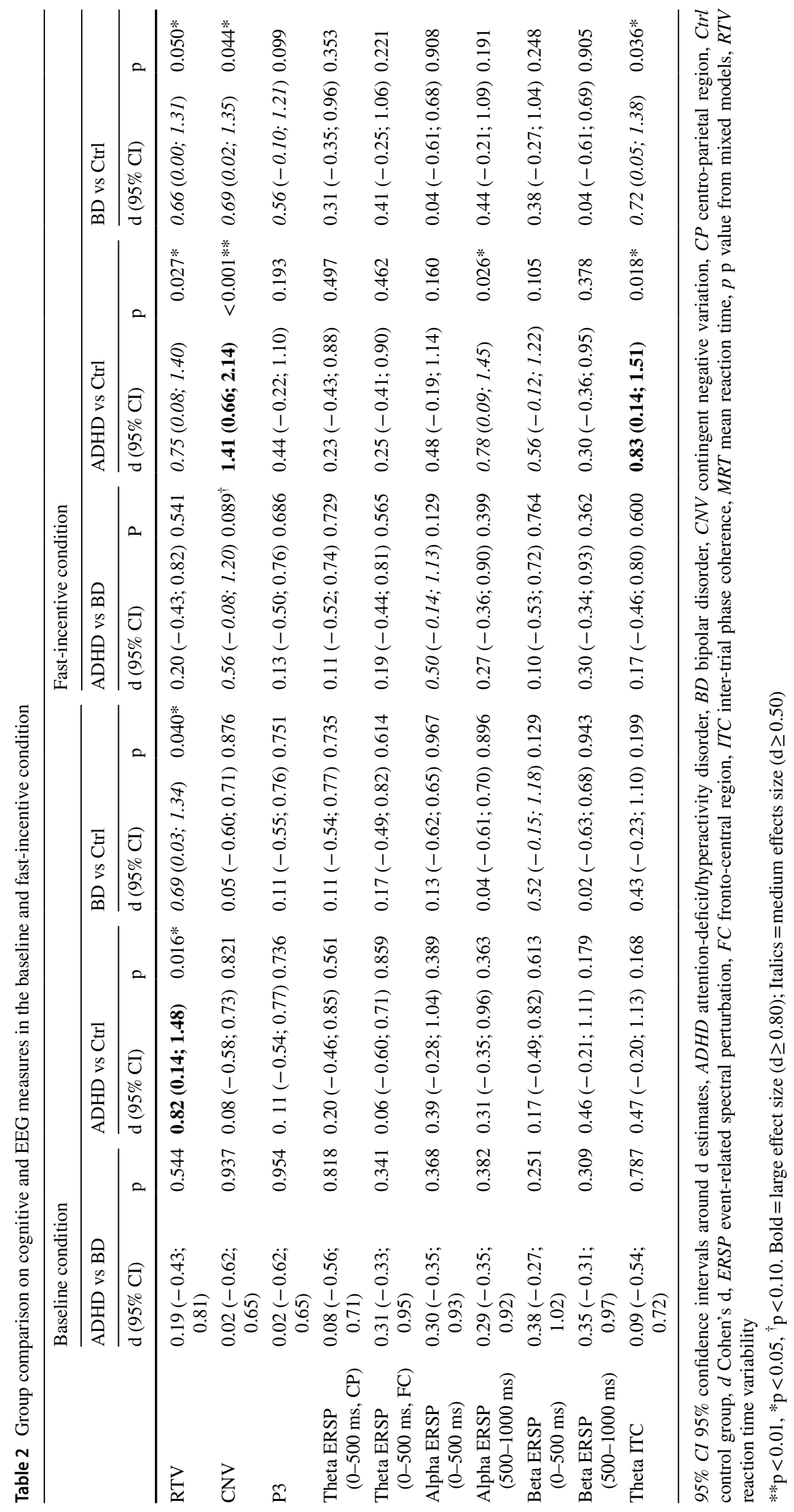


Table 3 Comparison of condition effects within group and between groups

\begin{tabular}{|c|c|c|c|c|c|c|c|c|c|}
\hline & \multicolumn{3}{|c|}{ Within-group differences } & \multicolumn{6}{|c|}{ Between-group differences } \\
\hline & \multirow{2}{*}{$\begin{array}{l}\text { ADHD } \\
\mathrm{p}\end{array}$} & \multirow{2}{*}{$\begin{array}{l}\mathrm{BD} \\
\mathrm{p}\end{array}$} & \multirow{2}{*}{$\begin{array}{l}\text { Ctrl } \\
\mathrm{p}\end{array}$} & \multicolumn{2}{|l|}{ ADHD vs BD } & \multicolumn{2}{|l|}{ ADHD vs Ctrl } & \multicolumn{2}{|l|}{ BD vs Ctrl } \\
\hline & & & & $\mathrm{d}(95 \% \mathrm{CI})$ & $\mathrm{p}$ & $\mathrm{d}(95 \% \mathrm{CI})$ & $\mathrm{p}$ & $\mathrm{d}(95 \% \mathrm{CI})$ & $\mathrm{p}$ \\
\hline RTV & $<0.001 * *$ & $<0.001 * *$ & $<0.001 * *$ & $\begin{array}{l}0.01(-0.61 \\
0.93)\end{array}$ & 0.982 & $\begin{array}{l}0.22(-0.42 \\
0.86)\end{array}$ & 0.507 & $\begin{array}{l}0.30(-0.35 \\
0.94)\end{array}$ & 0.366 \\
\hline $\mathrm{CNV}$ & $0.019^{*}$ & $<0.001 * *$ & $<0.001^{* *}$ & $\begin{array}{l}0.59(-0.08 \\
1.24)\end{array}$ & $0.083 \dagger$ & $1.17(0.44 ; 1.87)$ & $0.002 * *$ & $\begin{array}{l}0.59(-0.09 \\
1.25)\end{array}$ & $0.088 \dagger$ \\
\hline P3 & 0.723 & 0.331 & $0.026^{*}$ & $\begin{array}{l}0.08(-0.56 \\
0.72)\end{array}$ & 0.814 & $\begin{array}{l}0.49(-0.19 \\
1.16)\end{array}$ & 0.159 & $0.68(0.12 ; 1.32)$ & $0.048 *$ \\
\hline $\begin{array}{l}\text { Theta ERSP } \\
(0-500 \mathrm{~ms}, \mathrm{CP})\end{array}$ & $0.039 *$ & $0.003 * *$ & $0.085 \dagger$ & $\begin{array}{l}0.19(-0.45 \\
0.83)\end{array}$ & 0.567 & $\begin{array}{l}0.03(-0.63 \\
0.69)\end{array}$ & 0.930 & $\begin{array}{l}0.21(-0.45 \\
0.86)\end{array}$ & 0.543 \\
\hline $\begin{array}{l}\text { Theta ERSP } \\
(0-500 \mathrm{~ms}, \mathrm{FC})\end{array}$ & $0.004 *$ & $<0.001 * *$ & $0.056 \dagger$ & $\begin{array}{l}0.40(-0.25 \\
1.05)\end{array}$ & 0.231 & $\begin{array}{l}0.17(-0.49 \\
0.84)\end{array}$ & 0.612 & $\begin{array}{l}0.55(-0.11 \\
1.22)\end{array}$ & 0.106 \\
\hline $\begin{array}{l}\text { Alpha ERSP } \\
(0-500 \mathrm{~ms})\end{array}$ & $0.001 * *$ & $<0.001^{* *}$ & $<0.001 * *$ & $\begin{array}{l}0.44(-0.21 \\
1.09)\end{array}$ & 0.188 & $\begin{array}{l}0.44(-0.23 \\
1.10)\end{array}$ & 0.202 & $\begin{array}{l}0.05(-0.60 \\
0.70)\end{array}$ & 0.879 \\
\hline $\begin{array}{l}\text { Alpha ERSP } \\
\quad(500-1000 \mathrm{~ms})\end{array}$ & 0.568 & 0.510 & $<0.001 * *$ & $\begin{array}{l}0.13(-0.52 \\
0.77)\end{array}$ & 0.701 & $0.71(0.02 ; 1.39)$ & $0.045^{*}$ & $\begin{array}{l}0.52(-0.15 \\
1.18)\end{array}$ & 0.132 \\
\hline $\begin{array}{l}\text { Beta ERSP } \\
\quad(0-500 \mathrm{~ms})\end{array}$ & $<0.001 * *$ & $<0.001 * *$ & $<0.001 * *$ & $0.69(0.02 ; 1.35)$ & $0.044 *$ & $0.72(0.03 ; 1.40)$ & $0.040^{*}$ & $\begin{array}{l}0.05(-0.61 \\
0.70)\end{array}$ & 0.885 \\
\hline $\begin{array}{l}\text { Beta ERSP } \\
\quad(500-1000 \mathrm{~ms})\end{array}$ & 0.104 & $0.007 * *$ & $0.054 \dagger$ & $1.05(0.35 ; 1.73)$ & $0.003 * *$ & $0.87(0.17 ; 1.56)$ & $0.014 *$ & $\begin{array}{l}0.14(-0.52 \\
0.79)\end{array}$ & 0.683 \\
\hline Theta ITC & $0.083 \dagger$ & $0.018 *$ & $<0.001 * *$ & $\begin{array}{l}0.16(-0.49 \\
0.80)\end{array}$ & 0.634 & $\begin{array}{l}0.43(-0.25 \\
1.09)\end{array}$ & 0.216 & $\begin{array}{l}0.30(-0.36 \\
0.95)\end{array}$ & 0.379 \\
\hline
\end{tabular}

95\% CI 95\% confidence intervals around d estimates, $A D H D$ attention-deficit/hyperactivity disorder, $B D$ bipolar disorder, $C N V$ contingent negative variation, $C P$ centro-parietal region, $C t r l$ control group, $d$ Cohen's d, ERSP event-related spectral perturbation, $F C$ fronto-central region, $I T C$ inter-trial phase coherence, $M R T$ mean reaction time, $p \mathrm{p}$ value from mixed models, $R T V$ reaction time variability

$* * \mathrm{p}<0.01, * \mathrm{p}<0.05, \dagger \mathrm{p}<0.10$. Bold $=$ large effect size $(\mathrm{d} \geq 0.80)$; Italics $=$ medium effects size $(\mathrm{d} \geq 0.50)$.

\section{Event-Related Power (ERSP)}

\section{Theta}

No effects of group $(\mathrm{p}=0.96)$, condition $(\mathrm{p}=0.11)$ or group-by-condition-by-time interaction $(\mathrm{p}=0.94)$ emerged for theta ERSP. After removing the three-way interaction, there were no significant group or group-bycondition interaction effects on this measure $(p>0.61)$, and a significant main effect of condition emerged in the $0-500 \mathrm{~ms}$ window $(\mathrm{p}<0.001)$ but not in the $500-1000 \mathrm{~ms}$ window $(\mathrm{p}=0.41)$. In the $0-500 \mathrm{~ms}$ window, a significant within-group decrease from the baseline to the fast-incentive condition emerged in theta ERSP for the ADHD and BD groups, and at trend level for the control group (Table 3), but there were no group differences in the degree of change between conditions (Table 3). An additional analysis examined the event-related theta ERSP that was evident also at fronto-central regions (Fig. S3, Supplementary material), yielding the same results as found for parietal theta power (Tables 2, 3).

\section{Alpha}

A main effect of condition $(\mathrm{p}<0.001)$, but no effects of group $(p=0.25)$ or group-by-condition-by-time interaction $(p=0.23)$, emerged for alpha ERSP. After removing the three-way interaction, there was a significant effect of condition $(p<0.001)$, but no significant group $(\mathrm{p}=0.30)$ or group-by-condition interaction effects in the $0-500 \mathrm{~ms}$ time window for this measure $(p=0.48)$. All three groups showed a significant within-group decrease in alpha ERSP (i.e., increase in alpha suppression) in the change from the baseline to the fast-incentive condition (Table 3), but there were no group differences in the degree of change between conditions. In the 500-1000 ms window, a main effect of condition $(p=0.01)$, a trend-level group-bycondition interaction $(p=0.08)$, but no main effect of group $(p=0.23)$, emerged for alpha ERSP. Post-hoc tests showed no differences between groups in the baseline condition (Table 2). In the fast-incentive condition, the ADHD group showed a significantly decreased alpha ERSP (i.e., lower alpha suppression) compared to controls (Fig. 2). The BD group did not differ from the other groups. A significant within-group 
decrease from the baseline to the fast-incentive condition in alpha ERSP (i.e., increase in alpha suppression) emerged for the control group, but not for the ADHD or BD groups (Table 3). The ADHD group showed a significantly lower degree of change between conditions than the control group in this measure, while the BD group did not differ from the other groups (Table 3).

\section{Beta}

A significant main effect of condition $(\mathrm{p}<0.001)$, but no significant effect of group $(p=0.75)$ or group-by-conditionby-time interaction $(\mathrm{p}=0.61)$, emerged for beta ERSP. After removing the three-way interaction, there was no significant group effects in either time window $(p>0.25)$, but there were significant condition $(\mathrm{p}<0.001)$ and trend-level group-bycondition interaction $(p=0.06)$ effects in the in the $0-500 \mathrm{~ms}$ window, and significant group-by-condition interaction $(\mathrm{p}=0.01)$ and trend-level condition $(\mathrm{p}=0.08)$ effects in the 500-1000 ms window. A significant within-group decrease in beta ERSP (i.e., increase in beta suppression) from the baseline to the fast-incentive condition emerged for all groups in the 0-500 ms window, but only for control and BD groups in the 500-1000 ms window (Table 3; Fig. 3). The ADHD group differed from the $\mathrm{BD}$ and control groups in the degree of change in beta ERSP between conditions in both time windows, while the BD and control groups did not differ from one another (Table 3).

\section{Theta Phase Consistency (ITC)}

A main effect of group $(\mathrm{p}=0.03)$ and condition $(\mathrm{p}<0.001)$, but no group-by-condition interaction $(p=0.41)$, emerged for theta ITC in the 0-500 ms window. Post-hoc tests showed no differences between groups in the baseline condition (Table 2). In the fast-incentive condition, theta ITC was significantly decreased (i.e., phase was more variable) in the ADHD and $\mathrm{BD}$ groups compared to the control group, with no differences between ADHD and BD groups (Fig. 4). A significant withingroup increase in theta ITC (i.e., decrease in phase variability) from the baseline to the fast-incentive condition emerged in the control and BD groups, and at trend-level in the ADHD group (Table 3), but no differences between groups emerged in the degree of change between conditions. Further analyses compared groups prior to target onset, and found no differences in theta ITC before target appearance (Supplementary material).

\section{Discussion}

In this comparison between ADHD and BD on cognitive, ERP and brain-oscillatory markers of attentional processes, women with ADHD and women with BD showed overlapping impairments in fluctuations in attentional performance (RTV), neural variability (theta ITC) and neural response preparation (CNV). Individuals with either disorder further displayed a similar inability to adjust neural attention allocation (P3) and activation (alpha suppression) from a baseline to a fast-paced and rewarded condition, suggesting no adaptation to a changed context in these processes. Additional disorder-specific alterations in alpha and beta suppression were displayed by women with ADHD only, but impairments in most processes were shared between the two disorders. By examining both ERP and fine-grained brainoscillatory indices of brain activity, these findings reveal novel neural mechanisms of shared attentional dysfunction in ADHD and BD, which potentially underlie some of the common symptoms in both disorders.

At the cognitive level, both ADHD and BD groups showed increased RTV in both task conditions, indicating more frequent fluctuations in response speed and impairments in the ability to sustain attention during the task. Increased RTV in both disorders is consistent with our results with this sample using a cued CPT task (Michelini et al. 2016), and previous studies on ADHD (Cheung et al. 2016; Kofler et al. 2013; Kuntsi et al. 2010) and BD (Bora et al. 2006; Brotman et al. 2009; Moss et al. 2016). We further show novel evidence of intra-individual variability also at the neural level in the phase of theta oscillations in both women with ADHD and women with BD. Low phase variability over trials is thought to reflect an adaptive mechanism to maintain stable neural processing of a stimulus (Makeig et al. 2004; Papenberg et al. 2013). The increased variability in theta oscillations, previously reported in adolescents with ADHD (Groom et al. 2010; McLoughlin et al. 2014), thus points to increased variability in the timing of evoked theta responses to targets over trials in adults with ADHD and BD (Cavanagh et al. 2009; McLoughlin et al. 2014). Although these differences emerged as significant only in the fast-incentive condition, the group-by-condition interaction was not significant, suggesting that there may be subtle differences also in the baseline condition, non-significant in this sample. Further analyses in the pre-stimulus window indicated that, compared to individuals with ADHD or BD, control women displayed greater phase consistency upon target presentation, but lower consistency before targets. As such, with presentations of targets across trials, the controls displayed a consistent alignment and increase in consistency in the phase of theta (called phase resetting) (Lakatos et al. 2009; Palaniyappan et al. 2012) from the low consistency observed in the pre-stimulus window. This mechanism may be lacking in women with either ADHD or BD as indicated by the more frequent fluctuations in this neural mechanism across trials. Overall, our findings of increased variability in cognitive and neural processes in women with ADHD or BD indicate an overlap in the neural underpinnings of impaired 
attentional fluctuations in both disorders, which may point to common neurobiological dysfunctions.

By further examining pre-stimulus response preparation in $\mathrm{ADHD}$ and $\mathrm{BD}$, we found shared preparatory impairments, as indicated by reduced $\mathrm{CNV}$, in both clinical groups in the fast-incentive condition. This finding is consistent with our previous results in this sample using a CPT task (Michelini et al. 2016), and in adolescents and young adults with ADHD using the same task employed in this study (Cheung et al. 2017). Suggestive (trend-level) differences between ADHD and BD in this measure may also indicate more pronounced CNV impairment in ADHD, although this awaits replication in future studies. The pattern for P3 amplitude in response to targets, which was not different from controls in either ADHD or BD groups, indicates that women with either disorder may not be impaired in this ERP of attentional allocation. This result is consistent with our previous study with this sample (Michelini et al. 2016), showing intact P3s following cue and target stimuli, and other previous studies reporting normal attentional $\mathrm{P} 3$ amplitudes in adults with ADHD (Barry et al. 2009; McLoughlin et al. 2010) or BD (Bestelmeyer 2012). Yet, this P3 finding does not align with our previous larger-scale investigation using this task in ADHD, where our predominantly-male group of adolescents and young adults with ADHD (mean age: 18 years) showed a reduced $\mathrm{P} 3$ in the baseline condition (with a small effect size) compared to controls (Cheung et al. 2017). In the current study, the intact target $P 3$ in ADHD may be due to gender or age, the present study being the first on this task using an all-female and all-adult sample (mean age: 37 years). In addition, the ADHD group had lower IQ than the control group in our previous study, and the ADHD-control difference on the P3 was non-significant when IQ was controlled for (Cheung et al. 2017). The lack of IQ differences between groups in the current sample may have contributed to the lack of group differences in the P3. Taken together, these findings indicate that both ADHD and $\mathrm{BD}$ are associated with reduced ERP activity of attentional preparation and anticipation of motor responses.

With faster target presentation and incentives, further shared impairments between ADHD and BD emerged in adjustments between conditions. These task manipulations, originally designed in ADHD studies to reward more consistent response times, produced comparable reductions in RTV in clinical and control groups. At the neural level, women with ADHD, and potentially (at trend-level) with $\mathrm{BD}$, displayed significantly reduced increases in CNV amplitude compared to controls, and no improvements in allocation of attentional resources (P3) (Polich 2007) or attentional selection (alpha suppression) (Klimesch 2012). The novel finding of a reduced ability to increase alpha suppression with task demands in both disorders points to a common inability in individuals with ADHD and BD to regulate brain activity implicated in attentional selection processes (Klimesch 2012; Klimesch et al. 2007). A reduced adjustment in the response preparation $\mathrm{CNV}$ in women with $\mathrm{ADHD}$ replicates our previous findings in adolescents and young adults with the disorder (Cheung et al. 2017). Yet, in the P3, neither of the clinical groups showed the improvement between conditions displayed by controls. This pattern for the P3 contrasts with our previous findings using this task in a sample of adolescents and young adults with ADHD, where the ADHD group showed improvements between conditions in the P3, which were greater than those observed in the control group, suggesting malleability in this attentional ERP component in ADHD (Cheung et al. 2017). Similarly, these results in ADHD do not align with studies in children, adolescents and young adults indicating greater RTV malleability and improvements in ADHD than in neurotypical samples (Andreou et al. 2007; Cheung et al. 2017; Kuntsi et al. 2013, 2009). A possible explanation for the inconsistencies in P3 and RTV adjustments is the age difference between the samples of current and previous studies: it could be hypothesized that adults with ADHD, compared to younger individuals, may be less sensitive to task manipulations in these processes. Gender effects represent another possible reason for inconsistencies with previous studies based on predominantly-male samples (Andreou et al. 2007; Cheung et al. 2017). Longitudinal studies and replications in larger samples, including individuals of both sexes, are needed to examine potential developmental and gender effects on the malleability of markers of attentional processes in ADHD.

While most impairments were shared between ADHD and $\mathrm{BD}$, we further found impairments specific to ADHD relative to controls, which were not displayed by women with BD. Women with ADHD displayed a dysfunction in attentional selection, as indexed by lower alpha power suppression in response to targets in the fast-incentive condition (Klimesch 2012; Klimesch et al. 2007). These results are consistent with previous studies reporting attenuated event-related alpha suppression in ADHD (Hasler et al. 2016; Lenartowicz et al. 2014; Mazaheri et al. 2014; Missonnier et al. 2013). In addition, in the change from the baseline to the fast-incentive condition, individuals with ADHD were specifically associated with lower adjustments in the suppression of beta power than in individuals with $\mathrm{BD}$ and controls, indicating reduced improvements in neural mechanisms associated with response execution (Bickel et al. 2012; Mazaheri et al. 2014). The lack of a difference between women with $\mathrm{BD}$ and controls on measures of alpha and beta power suppression has not been reported in previous studies of $\mathrm{BD}$, which measured event-related power extracted from averaged ERP responses and thus could not capture event-related power suppressions. Future investigations using the finer-grained time-frequency methods employed in this study are needed to confirm typical profiles 
in alpha and beta power suppression measures in individuals with BD. While the ADHD-specific impairment in alpha suppression did not distinguish women with ADHD from women with $\mathrm{BD}$, the reduction in the adjustment in beta power suppression with task demands significantly differentiated the two clinical groups. The latter brain-oscillatory process may thus represent neurobiological dysfunctions specific to ADHD, which may potentially help delineate ADHD from BD in adults.

The following limitations should be considered when interpreting our findings. First, although the groups were matched on gender, age and IQ, there were differences in the prescribed medications that participants were taking. We asked participants with ADHD to stop taking stimulant medication $48 \mathrm{~h}$ before assessments, but it was not possible, for ethical reasons, to ask participants to stop mood-stabilizing, anti-psychotic or antidepressant medications. Medication effects are difficult to control for in cross-disorder studies where different groups are prescribed different treatments, resulting in a limited number of participants within medication subgroups. However, previous studies suggest that medication may show positive effects (reducing differences from controls) or no effects on cognitive-EEG measures (Anderer et al. 2002; Degabriele and Lagopoulos 2017; Galletly et al. 2005; Karaaslan et al. 2003). As such, it is unlikely that the significant group differences reported in this study reflect confounding medication effects. Yet, the possibility remains that the lack of differences between clinical groups and the control group on some measures (especially for the BD group, where the majority of individuals were taking medication) may be due to medication effects, which may have attenuated case-control differences. Future studies on samples including non-medicated individuals or a higher number of individuals in each medication sub-group are needed to clarify this issue. Second, while the two task conditions were matched on number of trials, they differed in duration and in length of the fore-period between warning and target stimuli. While we obtained comparable findings in RTV with length-matched segments, ERP/EEG analyses could not be repeated on length-matched segments, as doing so would have produced insufficient number of trials in the baseline condition to obtain reliable ERP/EEG indices. In addition, the different fore-periods and the use of a $0.25 \mathrm{~Hz}$ high-pass filter may reduce comparability of preparatory activity between the conditions. Yet, the analysis of the CNV (showing typical topographies at central sites) and the further analyses of EEG activity in the warningtarget interval under fast-incentive conditions (Supplementary material) allowed detailed investigation of neural preparatory processes in this latter condition. Future studies could examine stimulus-related and preparatory processes in ADHD and BD using other tasks, as well as examine the influences on slower frequencies on the CNV. Third, although the current study and previous analyses on this sample (Michelini et al. 2016; Rommel et al. 2016) represent the most comprehensive comparisons between ADHD and $\mathrm{BD}$ on cognitive, ERP and EEG markers to date, the sample is relatively small. While several significant differences between groups emerged with medium-to-large effects with current sample sizes, larger studies are needed to confirm these results and further investigate subtler impairments in ADHD and BD. Finally, the adult participants in the clinical groups recruited for this study showed higher than expected IQ scores, which did not differ from IQ scores in the control group. Future replication in samples with a wider range of IQs is required in order to generalize these findings to more typical clinical populations.

Taken together, these findings further our understanding of the neural underpinnings of attentional impairments in both disorders, and provide new evidence into the overlap and specificity of impairments in these processes in women with ADHD and BD. The shared markers of attentional dysfunctions may represent biomarkers for both disorders. The shared atypical neural profiles related to attentional processes may underlie similarities in behavioral symptoms (e.g., distractibility) between ADHD and BD, which can lead to difficulty in delineating between ADHD and BD and incorrect treatment decisions. Finally, since ADHD and BD show genetic overlap (Lee et al. 2013; Song et al. 2015; van Hulzen et al. 2016), and increased attentional fluctuations may represent candidate markers of genetic/familial risk for both disorders (Adleman et al. 2014; Andreou et al. 2007), future studies could examine whether shared genetic factors may underlie overlapping attentional dysfunctions in ADHD and BD.

Acknowledgements We thank all who made this research possible: The National Adult ADHD Clinic at the South London and Maudsley Hospital, Dr Helen Costello, Prof Sophia Frangou, Prof Anne Farmer, Jessica Deadman, Hannah Collyer, Sarah-Jane Gregori, and all participants who contributed their time to the study. Dr Giorgia Michelini was supported by a $1+3 \mathrm{PhD}$ studentship awarded by the MRC Social, Genetic and Developmental Psychiatry Centre, Institute of Psychiatry, Psychology and Neuroscience, King's College London (G9817803). This project was supported by an Economic and Social Research Council studentship to Dr Viryanaga Kitsune (ES/100971X/1). Dr Giorgia Michelini and Prof Philip Asherson are supported by generous grants from the National Institute for Health Research Biomedical Research Centre for Mental Health at King's College London, Institute of Psychiatry, Psychology and Neuroscience and South London and Maudsley National Health Service (NHS) Foundation Trust. The funders had no role in the design and conduct of the study; collection, management, analysis, and interpretation of the data; preparation, review, or approval of the manuscript; and decision to submit the manuscript for publication.

\section{Compliance with Ethical Standards}

Conflict of interest Professor Jonna Kuntsi has given talks at educational events sponsored by Medice; all funds are received by King's 
College London and used for studies of ADHD. Prof Philip Asherson has received funding for research by Vifor Pharma, and has given sponsored talks and been an advisor for Shire, Janssen-Cilag, Eli-Lilly, Flynn Pharma and Pfizer, regarding the diagnosis and treatment of ADHD. All funds are received by King's College London and used for studies of ADHD. Prof Daniel Brandeis serves as an unpaid scientific advisor for an EU-funded Neurofeedback trial unrelated to the present work. The other authors report no conflicts of interest.

Open Access This article is distributed under the terms of the Creative Commons Attribution 4.0 International License (http://creativeco mmons.org/licenses/by/4.0/), which permits unrestricted use, distribution, and reproduction in any medium, provided you give appropriate credit to the original author(s) and the source, provide a link to the Creative Commons license, and indicate if changes were made.

\section{References}

Adleman NE, Yi JY, Deveney CM, Guyer AE, Leibenluft E, Brotman MA (2014) Increased intrasubject variability in response time in unaffected preschoolers at familial risk for bipolar disorder. Psychiatry Res 219:687-689. https://doi.org/10.1016/j.psych res.2014.06.047

Albaugh MD et al (2017) Inattention and reaction time variability are linked to ventromedial prefrontal volume in adolescents. Biol Psychiatry. https://doi.org/10.1016/j.biopsych.2017.01.003

Albrecht B et al (2013) Familiality of neural preparation and response control in childhood attention deficit-hyperactivity disorder. Psychol Med 43:1997-2011. https://doi.org/10.1017/s003329171 200270x

Altman EG, Hedeker D, Peterson JL, Davis JM (1997) The Altman Self-Rating Mania Scale. Biol Psychiatry 42:948-955. https://doi. org/10.1016/s0006-3223(96)00548-3

Anderer P, Saletu B, Semlitsch HV, Pascual-Marqui RD (2002) Perceptual and cognitive event-related potentials in neuropsychopharmacology: methodological aspects and clinical applications (pharmaco-ERP topography and tomography). Methods Find Exp Clin Pharmacol 24(Suppl C):121-137

Andreou P et al (2007) Reaction time performance in ADHD: improvement under fast-incentive condition and familial effects. Psychol Med 37:1703-1715. https://doi.org/10.1017/s0033291707000815

Asherson P, Young AH, Eich-Hochli D, Moran P, Porsdal V, Deberdt W (2014) Differential diagnosis, comorbidity, and treatment of attention-deficit/hyperactivity disorder in relation to bipolar disorder or borderline personality disorder in adults. Curr Med Res Opin 30:1657-1672. https://doi.org/10.1185/03007 995.2014.915800

Atagun MI, Guntekin B, Ozerdem A, Tulay E, Basar E (2013) Decrease of theta response in euthymic bipolar patients during an oddball paradigm. Cogn Neurodyn 7:213-223. https://doi.org/10.1007/ s11571-012-9228-7

Babiloni C et al (2004) Human cortical responses during one-bit shortterm memory. A high-resolution EEG study on delayed choice reaction time tasks. Clin Neurophysiol 115:161-170

Banaschewski T, Brandeis D, Heinrich H, Albrecht B, Brunner E, Rothenberger A (2003) Association of ADHD and conduct disorder-brain electrical evidence for the existence of a distinct subtype. J Child Psychol Psychiatry 44:356-376

Barry RJ, Clarke AR, McCarthy R, Selikowitz M, Brown CR, Heaven PC (2009) Event-related potentials in adults with Attention-Deficit/Hyperactivity Disorder: an investigation using an inter-modal auditory/visual oddball task. Int J Psychophysiol 71:124-131. https://doi.org/10.1016/j.ijpsycho.2008.09.009
Basar E, Guntekin B, Atagun I, Turp Golbasi B, Tulay E, Ozerdem A (2012) Brain's alpha activity is highly reduced in euthymic bipolar disorder patients. Cogn Neurodyn 6:11-20. https://doi. org/10.1007/s11571-011-9172-y

Beck AT, Steer RA, Ball R, Ranieri W (1996) Comparison of beck depression inventories -IA and -II in psychiatric outpatients. J Pers Assess 67:588-597. https://doi.org/10.1207/s15327752j pa6703_13

Bestelmeyer PE (2012) The visual P3a in schizophrenia and bipolar disorder: effects of target and distractor stimuli on the P300. Psychiatry Res 197:140-144. https://doi.org/10.1016/j.psych res.2011.09.030

Bickel S, Dias EC, Epstein ML, Javitt DC (2012) Expectancy-related modulations of neural oscillations in continuous performance tasks. Neuroimage 62:1867-1876. https://doi.org/10.1016/j.neuro image.2012.06.009

Bora E, Vahip S, Akdeniz F (2006) Sustained attention deficits in manic and euthymic patients with bipolar disorder. Prog Neuropsychopharmacol Biol Psychiatry 30:1097-1102. https://doi. org/10.1016/j.pnpbp.2006.04.016

Brotman MA, Rooney MH, Skup M, Pine DS, Leibenluft E (2009) Increased intrasubject variability in response time in youths with bipolar disorder and at-risk family members. J Am Acad Child Adolesc Psychiatry 48:628-635. https://doi.org/10.1097/ CHI.0b013e3181a27527

Cavanagh JF, Cohen MX, Allen JJ (2009) Prelude to and resolution of an error: EEG phase synchrony reveals cognitive control dynamics during action monitoring. J Neurosci 29:98-105. https://doi. org/10.1523/jneurosci.4137-08.2009

Cheung CH, Rijsdijk F, McLoughlin G, Brandeis D, Banaschewski T, Asherson P, Kuntsi J (2016) Cognitive and neurophysiological markers of ADHD persistence and remission. Br J Psychiatry 208:548-555. https://doi.org/10.1192/bjp.bp.114.145185

Cheung CH, McLoughlin G, Brandeis D, Banaschewski T, Asherson P, Kuntsi J (2017) Neurophysiological correlates of attentional fluctuation in attention-deficit/hyperactivity disorder. Brain Topogr. 30:320-332

Chun J et al (2013) Can P300 distinguish among schizophrenia, schizoaffective and bipolar I disorders? An ERP study of response inhibition. Schizophr Res 151:175-184. https://doi.org/10.1016/j. schres.2013.10.020

Cohen J (1988) Statistical power analysis for the behavioral sciences, 2nd edn. Lawrence Erlbaum Associates, Hillsdale

Degabriele R, Lagopoulos J (2017) A review of EEG and ERP studies in bipolar disorder. Acta Neuropsychiatrica 21:58-66. https://doi. org/10.1111/j.1601-5215.2009.00359.x

Delorme A, Makeig S (2004) EEGLAB: an open source toolbox for analysis of single-trial EEG dynamics including independent component analysis. J Neurosci Methods 134:9-21. https://doi. org/10.1016/j.jneumeth.2003.10.009

DeLosAngeles D et al (2016) Electroencephalographic correlates of states of concentrative meditation. Int J Psychophysiol 110:27-39. https://doi.org/10.1016/j.jpsycho.2016.09.020

Dhar M, Been PH, Minderaa RB, Althaus M (2010) Information processing differences and similarities in adults with dyslexia and adults with Attention Deficit Hyperactivity Disorder during a Continuous Performance Test: a study of cortical potentials. Neuropsychologia 48:3045-3056. https://doi.org/10.1016/j.neuro psychologia.2010.06.014

Ethridge LE et al (2012) Neural activations during auditory oddball processing discriminating schizophrenia and psychotic bipolar disorder. Biol Psychiatry 72:766-774. https://doi.org/10.1016/j. biopsych.2012.03.034

Fridberg DJ, Hetrick WP, Brenner CA, Shekhar A, Steffen AN, Malloy FW, O’Donnell BF (2009) Relationships between auditory event-related potentials and mood state, medication, and comorbid 
psychiatric illness in patients with bipolar disorder. Bipolar Disord 11:857-866. https://doi.org/10.1111/j.1399-5618.2009.00758.x

Galletly CA, Clark CR, McFarlane AC (2005) Clozapine improves working memory updating in schizophrenia. Eur Neuropsychopharmacol 15:601-608. https://doi.org/10.1016/j.euron euro.2005.03.001

Grane VA, Brunner JF, Endestad T, Aasen IE, Kropotov J, Knight RT, Solbakk AK (2016) ERP correlates of proactive and reactive cognitive control in treatment-naive adult ADHD. PLoS ONE 11:e0159833. https://doi.org/10.1371/journal.pone.0159833

Groom MJ, Cahill JD, Bates AT, Jackson GM, Calton TG, Liddle PF, Hollis C (2010) Electrophysiological indices of abnormal errorprocessing in adolescents with attention deficit hyperactivity disorder (ADHD). J Child Psychol Psychiatry 51:66-76. https://doi. org/10.1111/j.1469-7610.2009.02128.x

Guntekin B, Emek-Savas DD, Kurt P, Yener GG, Basar E (2013) Beta oscillatory responses in healthy subjects and subjects with mild cognitive impairment. Neuroimage Clin 3:39-46. https://doi. org/10.1016/j.nicl.2013.07.003

Hasler R, Perroud N, Meziane HB, Herrmann F, Prada P, Giannakopoulos P, Deiber MP (2016) Attention-related EEG markers in adult ADHD. Neuropsychologia 87:120-133. https://doi. org/10.1016/j.neuropsychologia.2016.05.008

Hosang GM, Uher R, Maughan B, McGuffin P, Farmer AE (2012) The role of loss and danger events in symptom exacerbation in bipolar disorder. J Psychiatr Res 46:1584-1589. https://doi.org/10.1016/j. jpsychires.2012.07.009

Jacobs J, Hwang G, Curran T, Kahana MJ (2006) EEG oscillations and recognition memory: theta correlates of memory retrieval and decision making. Neuroimage 32:978-987. https://doi. org/10.1016/j.neuroimage.2006.02.018

James S-N et al. (2017) Peripheral hypoarousal but not preparationvigilance impairment endures in ADHD remission. J Atten Disord. https://doi.org/10.1177/1087054717698813

Jung TP, Makeig S, Humphries C, Lee TW, McKeown MJ, Iragui V, Sejnowski TJ (2000) Removing electroencephalographic artifacts by blind source separation. Psychophysiology 37:163-178

Kaiser S, Roth A, Rentrop M, Friederich HC, Bender S, Weisbrod M (2008) Intra-individual reaction time variability in schizophrenia, depression and borderline personality disorder. Brain Cogn 66:73-82. https://doi.org/10.1016/j.bandc.2007.05.007

Karaaslan F, Gonul AS, Oguz A, Erdinc E, Esel E (2003) P300 changes in major depressive disorders with and without psychotic features. J Affect Disord 73:283-287

Kitsune GL, Kuntsi J, Costello H, Frangou S, Hosang GM, McLoughlin G, Asherson P (2016) Delineating ADHD and bipolar disorder: a comparison of clinical profiles in adult women. J Affect Disord 192:125-133. https://doi.org/10.1016/j.jad.2015.12.024

Klimesch W (1999) EEG alpha and theta oscillations reflect cognitive and memory performance: a review and analysis. Brain Res Brain Res Rev 29:169-195

Klimesch W (2012) Alpha-band oscillations, attention, and controlled access to stored information. Trends Cogn Sci 16:606-617. https ://doi.org/10.1016/j.tics.2012.10.007

Klimesch W, Sauseng P, Hanslmayr S (2007) EEG alpha oscillations: the inhibition-timing hypothesis. Brain Res Rev 53:63-88. https ://doi.org/10.1016/j.brainresrev.2006.06.003

Kofler MJ, Rapport MD, Sarver DE, Raiker JS, Orban SA, Friedman LM, Kolomeyer EG (2013) Reaction time variability in ADHD: a meta-analytic review of 319 studies. Clin Psychol Rev 33:795811. https://doi.org/10.1016/j.cpr.2013.06.001

Kuntsi J, Klein C (2012) Intraindividual variability in ADHD and its implications for research of causal links. Curr Top Behav Neurosci 9:67-91. https://doi.org/10.1007/7854_2011_145
Kuntsi J, Rogers H, Swinard G, Börger N, van der Meere J, Rijsdijk F, Asherson P (2006) Reaction time, inhibition, working memory and 'delay aversion' performance: genetic influences and their interpretation. Psychol Med 36:1613-1624. https://doi. org/10.1017/S0033291706008580

Kuntsi J, Wood AC, Van Der Meere J, Asherson P (2009) Why cognitive performance in ADHD may not reveal true potential: findings from a large population-based sample. J Int Neuropsychol Soc 15:570-579. https://doi.org/10.1017/s135561770909081x

Kuntsi J et al (2010) Separation of cognitive impairments in attentiondeficit/hyperactivity disorder into 2 familial factors. Arch Gen Psychiatry 67:1159-1167. https://doi.org/10.1001/archgenpsy chiatry.2010.139

Kuntsi J et al (2013) Genetic analysis of reaction time variability: room for improvement? Psychol Med 43:1323-1333. https://doi. org/10.1017/s0033291712002061

Kuntsi J, Pinto R, Price TS, van der Meere JJ, Frazier-Wood AC, Asherson P (2014) The separation of ADHD inattention and hyperactivity-impulsivity symptoms: pathways from genetic effects to cognitive impairments and symptoms. J Abnorm Child Psychol 42:127-136. https://doi.org/10.1007/s10802-013-9771-7

Lakatos P, O'Connell MN, Barczak A, Mills A, Javitt DC, Schroeder CE (2009) The leading sense: supramodal control of neurophysiological context by attention. Neuron 64:419-430. https://doi. org/10.1016/j.neuron.2009.10.014

Lee SH et al (2013) Genetic relationship between five psychiatric disorders estimated from genome-wide SNPs. Nat Genet 45:984-994. https://doi.org/10.1038/ng.2711

Lenartowicz A et al (2014) Electroencephalography correlates of spatial working memory deficits in attention-deficit/hyperactivity disorder: vigilance, encoding, and maintenance. J Neurosci 34:1171-1182. https://doi.org/10.1523/jneurosci.1765-13.2014

$\mathrm{Li} \mathrm{Z}$ et al (2015) Contingent negative variation in patients with deficit schizophrenia or bipolar I disorder with psychotic features: measurement and correlation with clinical characteristics. Nord J Psychiatry 69:196-203. https://doi.org/10.3109/08039 488.2014.959562

Loo SK, Lenartowicz A, Makeig S (2015) Research review: use of EEG biomarkers in child psychiatry research - current state and future directions. J Child Psychol Psychiatry. https://doi.org/10.1111/ jcpp. 12435

Luck SJ (2014) An introduction to the event-related potential technique, 2nd edn. MIT Press, Cambridge

Maekawa $\mathrm{T}$ et al (2013) Altered visual information processing systems in bipolar disorder: evidence from visual MMN and P3. Front Hum Neurosci 7:403. https://doi.org/10.3389/fnhum.2013.00403

Makeig S, Debener S, Onton J, Delorme A (2004) Mining eventrelated brain dynamics. Trends Cogn Sci 8:204-210. https://doi. org/10.1016/j.tics.2004.03.008

Mazaheri A, Picton TW (2005) EEG spectral dynamics during discrimination of auditory and visual targets. Brain Res Cogn Brain Res 24:81-96. https://doi.org/10.1016/j.cogbrainres.2004.12.013

Mazaheri A, Fassbender C, Coffey-Corina S, Hartanto TA, Schweitzer JB, Mangun GR (2014) Differential oscillatory electroencephalogram between attention-deficit/hyperactivity disorder subtypes and typically developing adolescents. Biol Psychiatry 76:422429. https://doi.org/10.1016/j.biopsych.2013.08.023

McLoughlin G, Albrecht B, Banaschewski T, Rothenberger A, Brandeis D, Asherson P, Kuntsi J (2009) Performance monitoring is altered in adult ADHD: a familial event-related potential investigation. Neuropsychologia 47:3134-3142. https://doi.org/10.1016/j.neuro psychologia.2009.07.013

McLoughlin G, Albrecht B, Banaschewski T, Rothenberger A, Brandeis D, Asherson P, Kuntsi J (2010) Electrophysiological evidence for abnormal preparatory states and inhibitory 
processing in adult ADHD. Behav Brain Funct 6:66. https://doi. org/10.1186/1744-9081-6-66

McLoughlin G, Palmer JA, Rijsdijk F, Makeig S (2014) Genetic overlap between evoked frontocentral theta-band phase variability, reaction time variability, and attention-deficit/hyperactivity disorder symptoms in a twin study. Biol Psychiatry 75:238-247. https:// doi.org/10.1016/j.biopsych.2013.07.020

Merikangas KR et al (2011) Prevalence and correlates of bipolar spectrum disorder in the world mental health survey initiative. Arch Gen Psychiatry 68:241-251. https://doi.org/10.1001/archgenpsy chiatry.2011.12

Michelini G, Kitsune GL, Hosang GM, Asherson P, McLoughlin G, Kuntsi J (2016) Disorder-specific and shared neurophysiological impairments of attention and inhibition in women with attentiondeficit/hyperactivity disorder and women with bipolar disorder. Psychol Med 46:493-504. https://doi.org/10.1017/s003329171 5001877

Missonnier P et al (2013) EEG anomalies in adult ADHD subjects performing a working memory task. Neuroscience 241:135-146. https://doi.org/10.1016/j.neuroscience.2013.03.011

Moss RA, Finkelmeyer A, Robinson LJ, Thompson JM, Watson S, Ferrier IN, Gallagher P (2016) The impact of target frequency on intra-individual variability in euthymic bipolar disorder: a comparison of two sustained attention tasks. Front Psychiatry 7:106. https://doi.org/10.3389/fpsyt.2016.00106

Ode S, Robinson MD, Hanson DM (2011) Cognitive-emotional dysfunction among noisy minds: predictions from individual differences in reaction time variability. Cogn Emot 25:307-327. https ://doi.org/10.1080/02699931.2010.494387

Ozerdema A, Guntekind B, Atagune MI, Basar E (2013) Brain oscillations in bipolar disorder in search of new biomarkers. Suppl Clin Neurophysiol 62:207-221

Palaniyappan L, Doege K, Mallikarjun P, Liddle E, Francis-Liddle P (2012) Cortical thickness and oscillatory phase resetting: a proposed mechanism of salience network dysfunction in schizophrenia. Psychiatriki 23:117-129

Papenberg G, Hammerer D, Muller V, Lindenberger U, Li SC (2013) Lower theta inter-trial phase coherence during performance monitoring is related to higher reaction time variability: a lifespan study. Neuroimage 83:912-920. https://doi.org/10.1016/j.neuro image.2013.07.032

Pfurtscheller G (1981) Central beta rhythm during sensorimotor activities in man. Electroencephalogr Clin Neurophysiol 51:253-264

Pfurtscheller G, Lopes da Silva FH (1999) Event-related EEG/MEG synchronization and desynchronization: basic principles. Clin Neurophysiol 110:1842-1857

Polich J (2007) Updating P300: an integrative theory of P3a and P3b. Clin Neurophysiol 118:2128-2148. https://doi.org/10.1016/j.clinp h.2007.04.019

Posner MI, Petersen SE (1990) The attention system of the human brain. Annu Rev Neurosci 13:25-42. https://doi.org/10.1146/ annurev.ne.13.030190.000325

Ramos-Quiroga JA et al (2016) Criteria and concurrent validity of DIVA 2.0: a semi-structured diagnostic interview for adult ADHD. J Atten Disord. https://doi.org/10.1177/1087054716 646451

Rommel AS et al (2016) Commonalities in EEG spectral power abnormalities between women with ADHD and women with bipolar disorder during rest and cognitive performance. Brain Topogr. https://doi.org/10.1007/s10548-016-0508-0
Saville CW et al (2015) Increased reaction time variability in attentiondeficit hyperactivity disorder as a response-related phenomenon: evidence from single-trial event-related potentials. J Child Psychol Psychiatry 56:801-813. https://doi.org/10.1111/jcpp.12348

Skirrow C, Hosang GM, Farmer AE, Asherson P (2012) An update on the debated association between ADHD and bipolar disorder across the lifespan. J Affect Disord 141:143-159. https://doi. org/10.1016/j.jad.2012.04.003

Slusarek M, Velling S, Bunk D, Eggers C (2001) Motivational effects on inhibitory control in children with ADHD. J Am Acad Child Adolesc Psychiatry 40:355-363. https://doi.org/10.1097/00004 583-200103000-00016

Song J, Bergen SE, Kuja-Halkola R, Larsson H, Landen M, Lichtenstein P (2015) Bipolar disorder and its relation to major psychiatric disorders: a family-based study in the Swedish population. Bipolar Disord 17:184-193. https://doi.org/10.1111/bdi.12242

Szuromi B, Czobor P, Komlosi S, Bitter I (2011) P300 deficits in adults with attention deficit hyperactivity disorder: a meta-analysis. Psychol Med 41:1529-1538. https://doi.org/10.1017/s003329171 0001996

Tallon-Baudry C, Bertrand O, Delpuech C, Pernier J (1996) Stimulus specificity of phase-locked and non-phase-locked $40 \mathrm{~Hz}$ visual responses in human. J Neurosci 16:4240-4249

Tan D, Ozerdem A, Guntekin B, Atagun MI, Tulay E, Karadag F, Basar E (2016) Increased beta frequency $(15-30 \mathrm{~Hz})$ oscillatory responses in euthymic bipolar patients under lithium monotherapy. Clin EEG Neurosci 47:87-95. https://doi.org/10.1177/15500 59414561056

ter Huurne N, Onnink M, Kan C, Franke B, Buitelaar J, Jensen O (2013) Behavioral consequences of aberrant alpha lateralization in attention-deficit/hyperactivity disorder. Biol Psychiatry 74:227233. https://doi.org/10.1016/j.biopsych.2013.02.001

Torralva $\mathrm{T}$ et al (2011) Neuropsychological functioning in adult bipolar disorder and ADHD patients: a comparative study. Psychiatry Res 186:261-266. https://doi.org/10.1016/j.psychres.2010.08.007

Uebel $\mathrm{H}$ et al (2010) Performance variability, impulsivity errors and the impact of incentives as gender-independent endophenotypes for ADHD. J Child Psychol Psychiatry 51:210-218. https://doi. org/10.1111/j.1469-7610.2009.02139.x

Valko L et al (2009) Differences in neurophysiological markers of inhibitory and temporal processing deficits in children and adults with ADHD. J Psychophysiol 23:235-246. https://doi. org/10.1027/0269-8803.23.4.235

van Hulzen KJ et al (2016) Genetic overlap between attention-deficit/hyperactivity disorder and bipolar disorder: evidence from genome-wide association study meta-analysis. Biol Psychiatry. https://doi.org/10.1016/j.biopsych.2016.08.040

Wechsler D (1999) Wechsler abbreviated scale of intelligence (WASI). Harcourt Assessment, San Antonio

Willcutt EG (2012) The prevalence of DSM-IV attention-deficit/ hyperactivity disorder: a meta-analytic review. Neurotherapeutics 9:490-499. https://doi.org/10.1007/s13311-012-0135-8

Wood AC, Asherson P, van der Meere JJ, Kuntsi J (2010) Separation of genetic influences on attention deficit hyperactivity disorder symptoms and reaction time performance from those on IQ. Psychol Med 40:1027-1037. https://doi.org/10.1017/s003329170 999119x

Young RC, Biggs JT, Ziegler VE, Meyer DA (1978) A rating scale for mania: reliability, validity and sensitivity. Br J Psychiatry 133:429-435 